\title{
Raltegravir - an integrase inhibitor for antiretroviral therapy in HIV-1 infection
}

\author{
Janet Marianne Jackson \\ CSF Medical Communications Ltd., Auckland, New Zealand \\ Drugs in Context 2012 \\ DOI: http://dx.doi.org/10.7573/dic.212231
}

Citation: Jackson, JM. Raltegravir - an integrase inhibitor for antiretroviral therapy in HIV-1 infection. Drugs in Context: e212231. doi: $10.7573 /$ dic. 212231

Copyright: this is an open access article published under the terms of the Creative Commons License Deed (CG BY-NC-ND 3.0) which allows you to share, copy, distribute and transmit the work provided it is properly attributed. You may not use this work for commercial purposes. For further information on commercial use, contact publisher@justmedicalmedia.com or go to wrere.drugsincontext.com/copyright.

Search criteria: English language articles were identified by searching the PubMed database using the search terms "raltegravir", "MK0518" and "isentress". Abstracts were evaluated and selected for further review according to our standard protocols. Bibliographies of individual articles were also assessed for additional articles of interest and the manufacturer of raltegravir was invited to supply any additional data to that identified via the PubMed database.

Date of last literature search: 28 August 2008.

Conclusion: Raltegravir represents a novel class of antiretroviral drug, targeting viral integrase and inhibiting strand transfer of the virus into the host DNA. It is indicated for use in treatment-experienced adult patients who have evidence of viral replication. For patients with limited treatment options, raltegravir, as part of an optimised combination drug regimen, offers a valuable addition to the treatment regimen for viral suppression against HIV-1 infection resistant to standard therapy.

NB: This article was originally published by CSF Medical Communications Ltd (CSF) in Drugs in Context 2008;4(3):217-38. Drugs in Context and all CSF copyrights were acquired by Just Medical Media Ltd in 2009. 


\section{SUMMARY}

The death sentence once associated with HIV infection has been reduced to a chronic and debilitating life sentence due to the development of highly effective combination antiretroviral drug regimens. In spite of this, a continued increase in the global HIV infection rate reflects the ability of the virus to develop resistance against a wide range of drugs, resulting in a substantial proportion of all patients receiving antiretroviral therapy that harbour multi-drug resistant virus. The need for new antiretroviral drugs, which for the first 20 years consisted of additions to the existing classes targeting the viral reverse transcriptase and protease enzymes, led to the novel approach of targeting the viral integrase enzyme, which catalyses virus strand transfer and integration into host DNA. After 15 years of integrase drug development, raltegravir reached Phase III clinical trial and was the first integrase inhibitor to be approved for clinical use. In major Phase II and Phase III trials in clinically advanced, three-class antiretroviral, treatment-experienced adults, the safety and tolerability profile of raltegravir was similar to placebo and it is generally well tolerated with demonstrated potent efficacy in the virologic suppression of HIV-1 RNA levels and improved immunocompetence. Twice-daily dosing with $400 \mathrm{mg}$ raltegravir provided viral load reduction accompanied by increase in CD4 cell count up to 48 weeks. Patients with virologic failure during raltegravir treatment had virus with mutations associated with drug resistance. Raltegravir is available for twice daily oral administration at $400 \mathrm{mg}$, in combination with other anti-retroviral drugs, for the treatment of human HIV-1 infection in treatment-experienced adult patients with evidence of HIV-1 replication despite ongoing anti-retroviral therapy.

Key words: raltegravir, Isentress, HIV-1, antiretroviral, AIDS

\section{HUMAN IMMUNODEFICIENCY VIRUS INFECTION - A PERSPECTIVE}

\section{HIV and AIDS}

Acquired Immunodeficiency Syndrome (AIDS) was first reported in a small number of patients in 1981 and a few years later Human Immunodeficiency Virus (HIV) was identified as the pathogen responsible for infection of the CD4 T-lymphocytes resulting in AIDS. When AIDS was first identified as a viral disease anyone infected with the HIV-1 virus had a life expectancy of less than a year. The rapid development of drugs targeting the retroviral reverse transcriptase enzyme led to the introduction of the first effective therapy, zidovudine, in 1987. Antiretroviral therapy, in conjunction with the development of specific HIV antibodies used in sensitive tests for early detection of HIV infection, increased life expectancy but did not prevent the spread of the disease. During the 1990s new drug regimens were introduced which greatly reduced the mortality and morbidity associated with HIV infection and transformed it from a fatal to a chronic disease. ${ }^{1}$ However, despite these developments, the AIDS epidemic is still growing. It is estimated that there are 33 million people living with HIV worldwide with more than 700,000 cases in Western Europe (Figure 1).2,3

\section{Antiretroviral therapy}

\section{Viral life cycle}

Development of antiretroviral drugs for HIV therapy has been based on targeting enzymes critical for the three stages of the HIV life cycle: fusion, reverse transcription and insertion into the host DNA and proteolytic maturation. ${ }^{4}$

Once the virus has entered the host cell by fusion, the viral RNA is converted to doublestranded complementary DNA (cDNA) by 
Figure 1. Estimated number of people living with HIV and adult HIV prevalence, 1990-2007. (Reproduced with kind permission from UNAIDS Report on the global AIDS epidemic 2008. ${ }^{2}$ )

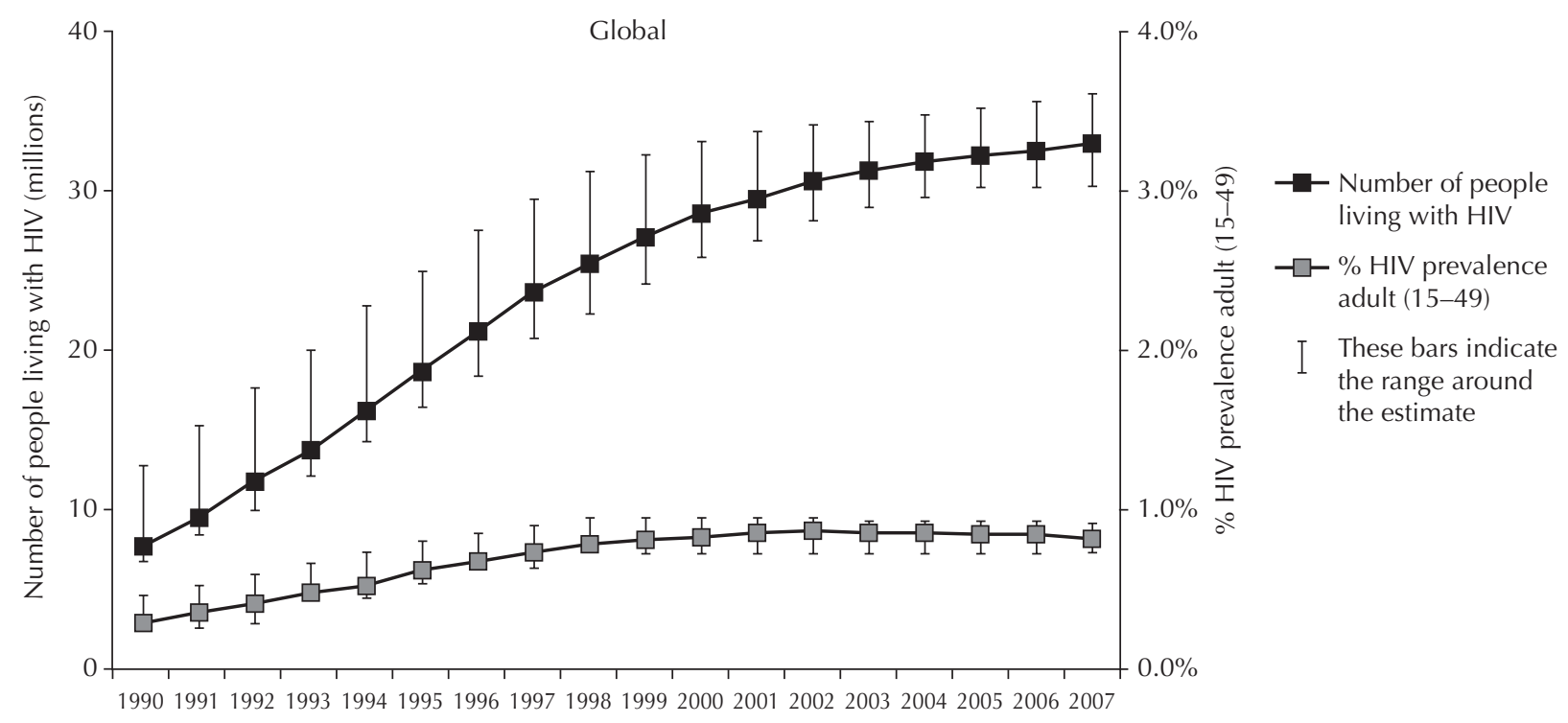

reverse transcriptase. Integrase then binds to the cDNA catalysing the $3^{\prime}$ processing reaction to produce the pre-integration complex. Integrase also catalyses the insertion of viral DNA into host DNA by strand transfer. This process is essential for viral gene expression and replication. The final stage of the HIV lifecycle is viral assembly, which is dependent on the cleavage of newly synthesised viral protein by viral protease to produce infectious virion (Figure 2).

\section{Combination therapy}

Antiretroviral therapy has been unable to suppress viral replication in all patients and due to the widespread emergence of viral resistance and toxicity with chronic therapy, new drugs and new therapeutic strategies have been sought and developed in an attempt to combat these problems. Increasing use of combination therapy has been widely successful in reducing viral load and restoring immunocompetence in HIV-1infected patients and there are now nearly 25 antiretroviral drugs licensed for treatment of HIV-1 infection. ${ }^{4}$
For patients with multi-drug resistant HIV-1 the use of highly active antiretroviral therapy (HAART) has been shown to reduce mortality and morbidity. This is also true for patients naive to therapy and for those who do not show drug resistance. In an ongoing HIV outpatient study in the US, data from 1255 patients were analysed over a period of 42 months between 1994 and 1997 to demonstrate a reduction in mortality rate and opportunistic infection which was attributable to the use of more intensive combination antiretroviral therapy. ${ }^{1}$ The positive effects of HAART on restoration of immune competence at advanced stages of HIV disease include reducing viral replication and viraemia, increase in CD4 cell numbers, reduction in CD8 cell numbers and a reduction in T-cell activation associated with decrease in retroviral activity. ${ }^{5}$ The HAART drug regimen became standard therapy and comprised a combination of different drug classes, usually three out of the first four existing drug classes, with a minimum of two nucleoside/ nucleotide reverse transcriptase inhibitors (NRTI), a protease inhibitor (PI) and/or a non-nucleoside reverse transcriptase inhibitor (NNRTI). ${ }^{4}$ 
Figure 2. The HIV replication cycle and drug targets, which are: $a$, fusion of HIV to the host cell; $b$, viral reverse transcriptase; $c$, viral protease; $d$, viral integrase. (Reproduced with kind permission from Pommier et al. ${ }^{17}$ )

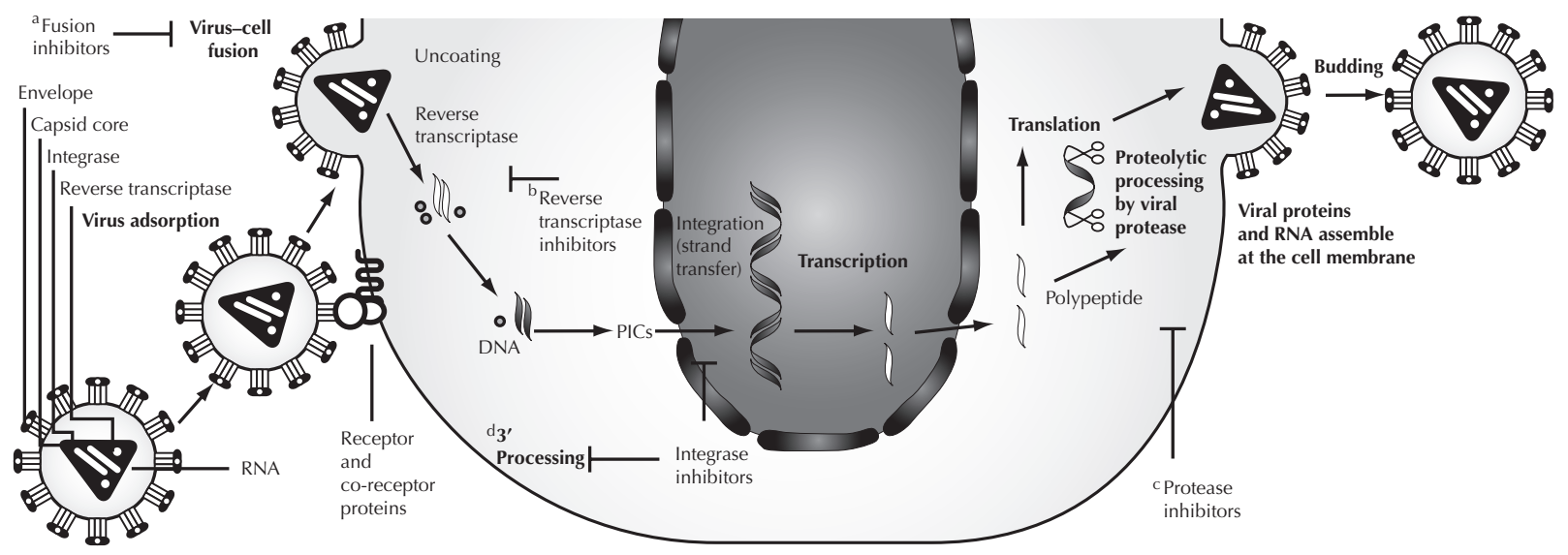

The most recent additions to the HAART regimen are the first fusion inhibitor, enfuvirtide, approved in 2003, followed in 2007 by maraviroc, a CCR5-receptor antagonist; CCR5 is a chemokine receptor, predominantly expressed on T-cells, monocytes and macrophages, which is used as co-receptor by HIV to enter its host cells. ${ }^{6}$

\section{Resistance to therapy and viral reservoirs}

Although HAART combinations have been able to reduce viral loads to undetectable levels, they have not been able to eradicate HIV-1 from infected patients, initially because of a poor understanding of the need for complete adherence. This has led to the selection of drugresistant strains of HIV-1. Long-term use of antiretroviral therapy therefore, is limited by the development of resistance to therapy and it is estimated that nearly $80 \%$ of treatmentexperienced patients worldwide have latent virus that is resistant to the current drug regimens. Drug resistance mutations can be transmitted and can persist for years in latent viral reservoirs. This contributes to the lack of responsiveness of some patients to antiretroviral therapy. ${ }^{4}$

Although combination therapy is more effective than monotherapy, as it reduces the emergence of drug-resistant virus, in about 50\% of patients, viral suppression is incomplete and these patients have been switched from one drug combination to another in an attempt to combat resistance. This is further complicated by the development of cross resistance between different drugs targeting the same enzyme. As a result, although HAART has been highly successful in suppressing HIV replication it has not led to HIV-1 eradication. ${ }^{7}$

HIV-1 is characterised by a rapid and highcopy replication rate and a correspondingly high mutation rate which results in its ability to develop rapid drug resistance. Replication-competent virus can accumulate in latent viral reservoirs, protected from immunological surveillance or from drug penetration. These reservoirs contain virus which evolves slowly, even during drug therapy, acquiring drug-resistant mutations. ${ }^{8}$ The most significant cellular reservoirs for $\mathrm{HIV}-1$ are resting CD4 memory cells containing integrated provirus. These cells have a long life span and are an important long-term reservoir, capable of producing infectious virus when stimulated. ${ }^{9}$ It has been found that GD8 cells are also infected by HIV-1, which has implications upon the success of antiretroviral therapy as these cells have an 
important role in eliciting an antiviral response. However these reservoirs appear to harbour virus that does not develop drug resistance. ${ }^{10}$ Other sites where viral reservoirs develop include the central nervous system and retina. ${ }^{8}$

Low levels of ongoing viral replication in viral reservoirs that persist even during treatment, produce detectable levels of viraemia, which leads to the selection of multiple drug-resistant strains of virus with extensive genotypic variation. This results in cross-resistance of various virus strains to other drugs targeting the same enzyme. ${ }^{8-10}$

In a UK collaborative multicentre cohort study, information obtained from 16,593 patients between 1996 and 2002 was analysed in terms of response to antiretroviral therapy. Of the patients receiving antiretroviral therapy, 38\% had experienced all three main drug classes within the study period, with a mean of four different drugs and up to $25 \%$ of these showed evidence of viral load increases and decrease in CD4 cell count during treatment (Table 1). The implications of this study were that although at a population level, virologic profiles of HIV patients receiving HAART continue to improve, an increasing proportion of HIVinfected patients are becoming resistant to therapy having exhausted all currently available treatment options. It was suggested that such patients experiencing treatment exhaustion would benefit from new drugs with low toxicity and no cross resistance with other dugs ${ }^{11}$

\section{Integrase inhibitors and raltegravir}

The HAART regimen is a long-term therapy. Chronic treatment with multiple drug combinations has led to severe adverse events, as many of these drugs were often not well tolerated for long-term use. This in turn contributed to poor patient compliance exacerbating the problem posed by the emergence of drug-resistant strains of HIV-1. The development of multi-drug

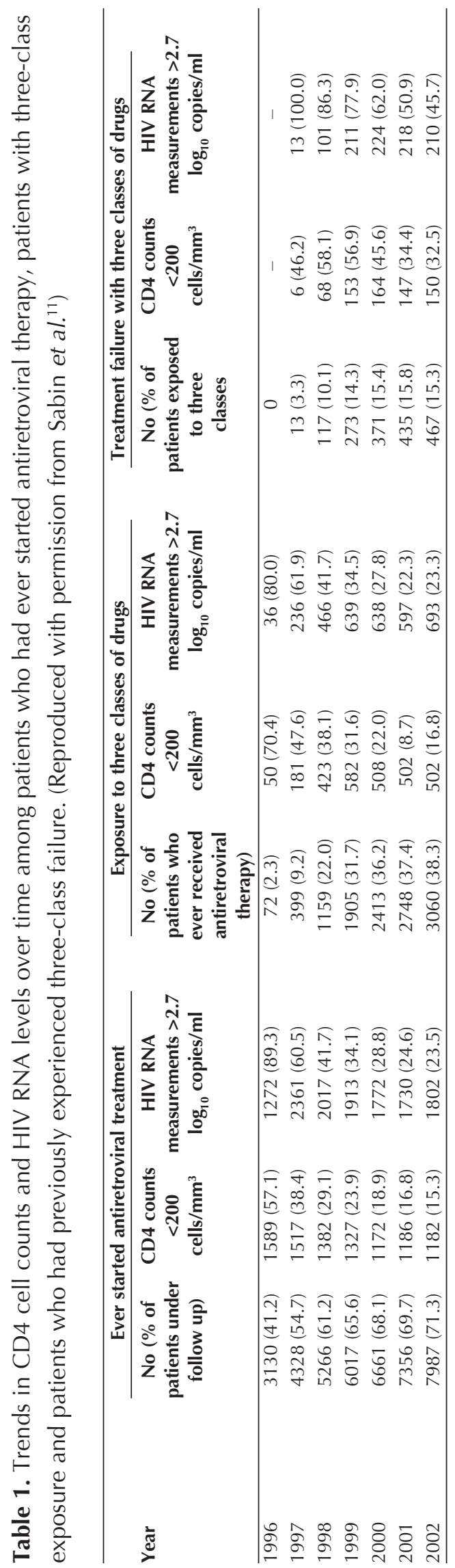


resistance in some patients increased the urgency to find a novel therapeutic approach and this drive led to the development of drugs targeting the third enzyme required for viral replication: HIV-1 integrase. ${ }^{6,12-15}$

Integrase inhibitors target the insertion of viral DNA into host genome by preventing strand transfer which is the final stage of provirus integration. This is also a good therapeutic target as there is no human homologue, reducing the potential for drug induced toxicity. Initially many integrase inhibitors were identified but the ability to inhibit integrase did not always convey potent antiviral activity. Understanding the relationship between the structure and function of HIV-1 integrase was an important step forward in the development of potent drugs that target this enzyme. In order to be classified as an integrase inhibitor a drug must meet four criteria. It must be active during the integration stage when the virus has completed reverse transcription (within 4-16 hours following infection), there must be reduced incorporation of viral DNA into the host DNA, integrase mutations must be found in drug-resistant virus and the drug must have no effect on virus with integrase mutations. ${ }^{16,17}$

Hazuda et al. ${ }^{16}$ developed a biochemical screen for effective integrase inhibitors and were able to identify a structurally distinct group of compounds with a diketo acid moiety that demonstrated greater potency in strand transfer assays, using recombinant integrase, which correlated with their activity in assays using preintegration complexes. These compounds also inhibited HIV-1 replication in cell culture. This method demonstrated that the antiviral activity could be directly related to functional inhibition of the strand transfer activity of integrase, without effect on viral DNA synthesis or processing in infected cells. Eventually raltegravir, formerly known as MK0518, was identified as the most potent and selective of a new class of integrase inhibitor, that prevents the strand transfer step, with antiviral activity against wild type and multi-drug resistant HIV-1 in vitro and in clinical isolates. $^{18,19}$

Raltegravir became the first of the integrase inhibitor class of drugs to enter Phase III clinical trial and was approved by the FDA in 2007 for use with other antiretroviral drugs agents in the treatment of HIV-1 infection. It was also granted marketing authorisation by the European Commission in December 2007 and given conditional approval by the European Medicines Agency (EMEA). As more evidence becomes available from ongoing clinical studies, these drugs will be reviewed by the EMEA.

With the addition of new antiretroviral drugs to established combination therapy regimens, new treatment guidelines have been established to assist in the decision-making process for managing the use of these drugs to achieve optimum clinical benefit with minimum toxicity and drug resistance. ${ }^{20,21}$

\section{PHARMACOLOGY}

\section{Mechanisms of action}

Raltegravir belongs to the hydroxypyrimidinone carboxamide class of compounds (Figure 3) and is structurally distinct from other integrase inhibitors like elvitegravir which is a hydroxyquinolone. ${ }^{15,16}$ Raltegravir inhibits the catalytic activity of HIV-1 integrase, by acting as a metal chelator interacting with divalent metals in the active site of the HIV-1 integrase. ${ }^{6,12,19}$ By inhibiting strand transfer activity raltegravir prevents insertion of linear viral DNA into the host genome.

The strand transfer activity of purified HIV-1 integrase was inhibited in vitro with an apparent $\mathrm{IC}^{50}$ of $2-7 \mathrm{nM}$ and with greater than 1000-fold selectivity for HIV-1 integrase than other phosphoryltransferases tested, including the polymerase and RNAse activities of HIV-1 reverse transcriptase and human polymerase $\alpha$, $\beta$ and $\gamma .{ }^{18}$ 
Figure 3. The chemical structure of raltegravir (Reproduced with kind permission from Evering and Markowitz ${ }^{6}$ )

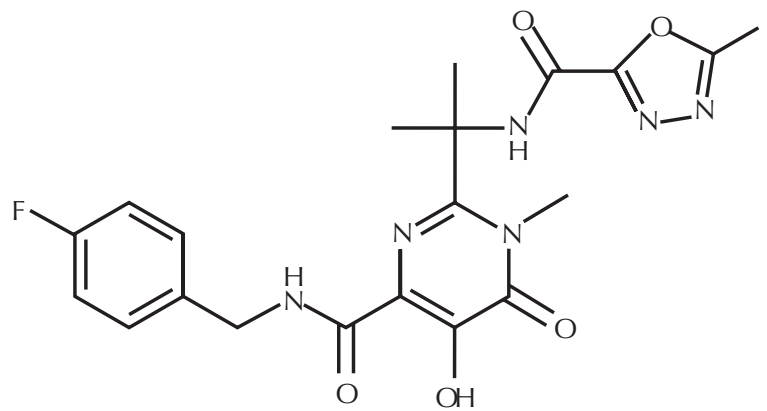

\section{Antiviral activity}

Raltegravir has potent antiviral activity in vitro, exhibiting 95\% inhibition of wild type HIV-1 $\left(\mathrm{IC}_{95}\right)^{18}$ at a mean concentration of $33 \mathrm{nM}$ (31 $\pm 20 \mathrm{nM}$ ) in human T-lymphoid cell cultures, infected with the cell-line adapted HIV-1 variant H9IIIB, in the presence of $50 \%$ human serum. ${ }^{24}$ It was further demonstrated that the antiviral activity of raltegravir in vitro was directly attributable to blocking integrase during infection, as quantitative PCR assays indicated no effect on synthesis of HIV cDNA whereas integration of viral DNA into cellular DNA was prevented with enhanced formation of dead-end 2-LTR circular DNA forms. ${ }^{18}$ Raltegravir was also found to have antiviral activity when tested against a range of $\mathrm{HIV}$ isolates, including isolates of HIV-2 and non-B clade subtypes of HIV-1, as well as primary clinical isolates resistant to other classes of antiretroviral drugs; protease inhibitors and reverse transcriptase inhibitors. Raltegravir was synergistic or additive in combination with all licensed antiretroviral drugs tested (tipranavir not tested). ${ }^{18}$

\section{Pharmacokinetics}

\section{Absorption and distribution in normal subjects}

A series of placebo-controlled studies were conducted in normal healthy volunteers to evaluate the pharmacokinetics of single and multiple doses of raltegravir. All pharmacokinetic values measured were doseproportional across a wide range of doses (1000-1600mg). ${ }^{22,23}$

In a single dose escalation study in normal subjects, raltegravir (10-1600 mg) or placebo was orally administered. Raltegravir was found to be rapidly absorbed with time to mean peak plasma concentration $\left(\mathrm{T}_{\max }\right)$ of $0.5-1.3$ hours in the fasted state. After multiple dosing every 12 hours for 10 days, steady state was achieved by two days. ${ }^{23}$

Concentration from mean peak plasma $\left(\mathrm{C}_{\max }\right)$ declined in a biphasic manner with an apparent half-life in the initial phase of one hour and a terminal half-life of 7-12 hours. Exposure to raltegravir, assessed by area under the concentration curve (AUG) and $\mathrm{G}_{\text {max }}$ increased dose proportionally over the dose range 100 $\mathrm{mg}$ to $1600 \mathrm{mg}$ and was similar in male and female subjects. There was little accumulation of raltegravir. ${ }^{23}$

Target trough level was $33 \mathrm{nM}$, based on $\mathrm{IC}_{95}$ value in vitro, and after single- or multipledose oral administration of $100 \mathrm{mg}$ or higher the geometric mean plasma concentration at 12 hours post dose $\left(\mathrm{C}_{12 \mathrm{hr}}\right)$ exceeded $33 \mathrm{nM} .^{23}$

Approximately $7-14 \%$ oral raltegravir was excreted in the urine unchanged and renal clearance was approximately $42-78 \mathrm{ml} / \mathrm{min} .{ }^{23}$

Raltegravir is approximately 83\% bound to human plasma protein over the concentration range of 2 to $10 \mu \mathrm{M}$. ${ }^{24}$

\section{Absorption and distribution in HIV-1-positive treatment naïve patients}

The pharmacokinetics of raltegravir have also been studied in treatment naïve patients 
with HIV-1 infection over a dose range of 100-600 mg, administered every 12 hours. Pharmacokinetic parameters were evaluated at day 10. Raltegravir was rapidly absorbed with a $\mathrm{T}_{\max }$ to $\mathrm{G}_{\max }$ of 1.7 hours without food, and 3 hours with food. The $\mathrm{AUC}_{0-12}$ increased with dose, (14.2 $\mathrm{mM} / \mathrm{h}$ at $400 \mathrm{mg}$ ) as did the geometric mean plasma concentrations at trough $\left(\mathrm{G}_{12 \mathrm{hr}}\right)$, which exceeded $33 \mathrm{nM}$ in all dosing groups. Geometric mean values for $\mathrm{C}_{\max }$ increased up to $400 \mathrm{mg}(4.5 \mathrm{mM})$ and then were similar for 400 and $600 \mathrm{mg}$ doses (Table 2). The half-life appeared consistent with studies done in normal volunteers, one hour initial half-life then 7-12 hours terminal half life. Although there were differences in pharmacokinetic parameters between patients similar reductions in viral load at 10 days were achieved by all patients. The

Table 2. Pharmacokinetic parameters of raltegravir at day 10 in treatment-naïve HIV-1-infected patients. (Reproduced with permission from Markowitz et al..25)

\begin{tabular}{|c|c|c|c|}
\hline $\begin{array}{l}\text { MK-0518 } \\
\text { Treatment group } \\
\text { (Twice daily) }\end{array}$ & $\mathbf{N}$ & $\begin{array}{c}\text { Geometric } \\
\text { Mean }(90 \% \mathrm{Cl})\end{array}$ & $\begin{array}{l}\text { Median } \\
\text { (Range) }\end{array}$ \\
\hline \multicolumn{4}{|l|}{$\overline{A \cup C}(\mu \mathrm{M} / \mathrm{h})$} \\
\hline $100 \mathrm{mg}$ & 7 & $5.7(4.5-7.3)$ & $5.2(4.2-10.2)$ \\
\hline $200 \mathrm{mg}$ & 7 & $9.2(6.4-13.1)$ & $11.3(4.6-15.9)$ \\
\hline $400 \mathrm{mg}$ & 6 & $14.2(7.6-26.6)$ & $18.4(3.8-28.8)$ \\
\hline $600 \mathrm{mg}$ & 8 & $14.6(8.3-25.8)$ & $16.3(2.9-53.9)$ \\
\hline Placebo & 0 & $\mathrm{~N} / \mathrm{A}$ & N/A \\
\hline \multicolumn{4}{|l|}{$\mathrm{C}_{\max }(\mu \mathrm{M})$} \\
\hline $100 \mathrm{mg}$ & 7 & $2.1(1.4-3.0)$ & $2.2(1.1-4.2)$ \\
\hline $200 \mathrm{mg}$ & 7 & $3.5(2.1-5.9)$ & $3.9(1.1-8.3)$ \\
\hline $400 \mathrm{mg}$ & 6 & $4.5(2.0-10.2)$ & $6.5(0.8-10.2)$ \\
\hline $600 \mathrm{mg}$ & 8 & $3.8(2.0-7.1)$ & $4.0(0.7-19.1)$ \\
\hline Placebo & 0 & $\mathrm{~N} / \mathrm{A}$ & $\mathrm{N} / \mathrm{A}$ \\
\hline \multicolumn{4}{|l|}{$C_{12 h}(\mu M)$} \\
\hline $100 \mathrm{mg}$ & 7 & $0.043(0.024-0.075)$ & $0.055(0.014-0.152)$ \\
\hline $200 \mathrm{mg}$ & 7 & $0.113(0.079-0.161)$ & $0.147(0.050-0.179)$ \\
\hline $400 \mathrm{mg}$ & 6 & $0.142(0.088-0.229)$ & $0.163(0.066-0.266)$ \\
\hline $600 \mathrm{mg}$ & 8 & $0.205(0.109-0.386)$ & $0.203(0.042-0.772)$ \\
\hline Placebo & 0 & N/A & N/A \\
\hline \multicolumn{4}{|l|}{$\mathrm{T}_{\max }(\mathrm{h})$} \\
\hline $100 \mathrm{mg}$ & 7 & $1.3(1.0-1.8)$ & $1.0(1.0-2.0)$ \\
\hline $200 \mathrm{mg}$ & 7 & $2.0(1.2-3.6)$ & $2.0(0.0-6.0)$ \\
\hline $400 \mathrm{mg}$ & 6 & $1.7(0.9-3.3)$ & $1.8(0.5-4.0)$ \\
\hline $600 \mathrm{mg}$ & 8 & $1.5(0.8-2.9)$ & $1.0(0.5-6.0)$ \\
\hline Placebo & 0 & N/A & N/A \\
\hline
\end{tabular}

plasma pharmacokinetic profile for raltegravir supports twice-daily dosing at $400 \mathrm{mg} .{ }^{24,25}$

In combination therapy pharmacokinetic values $\left(\mathrm{AUC}_{0-12 \mathrm{hr}}, \mathrm{C}_{\max }\right.$ and $\left.\mathrm{C}_{12 \mathrm{hr}}\right)$ were slightly higher compared with monotherapy, possibly due to drug interactions with tenofovir resulting in increased raltegravir exposure. ${ }^{26}$ Drug interaction studies in healthy volunteers also reported modestly higher $\mathrm{AUC}_{0-12 \mathrm{hr}}$ and $\mathrm{C}_{\max }$ values for raltegravir when coadministered with tenofovir but no effect was seen on $\mathrm{C}_{12 \mathrm{hr} \cdot{ }^{26}}$

\section{Effect of food}

A study to assess the effect of a standard highfat meal on a $400 \mathrm{mg}$ dose of raltegravir was conducted in 20 healthy adult subjects. A high-fat meal affected the rate, but not extent, of absorption of raltegravir. ${ }^{22}$ There was no clinically meaningful effect of taking food on the pharmacodynamic profile of raltegravir, although the effects of food may account for some observed variation in absorption and pharmacokinetic values. Raltegravir may be administered with or without food and most of the major studies in HIV-1-infected patients were conducted without regard to food. ${ }^{24}$

\section{Metabolism and clearance}

Absorption metabolism and excretion of raltegravir were studied in healthy male volunteers after a single oral dose of $200 \mathrm{mg}$ $(200 \mu \mathrm{Ci})$ radioactive $[\mathrm{G} 14]$ raltegravir. ${ }^{27}$ These studies demonstrated that raltegravir is eliminated primarily by metabolism in the liver by glucuronidation with uridine diphosphate glucuronosyl transferase (UGT1A1). Its main metabolite is the glucuronide M2, which has no antiretroviral activity. Raltegravir was eliminated in the urine $(32 \%)$ and faeces $(51 \%)$. The majority of excreted product in urine $(23 \%)$ was the glucuronide metabolite, with only $9 \%$ of active raltegravir. In faeces, only active raltegravir was present, most of which is likely to be derived from hydrolysis of the metabolite 
secreted in bile. Raltegravir was found to be the major circulating entity, accounting for $70 \%$ of the radioactivity; M2 accounted for the remainder. Therefore the antiretroviral activity can be attributed entirely to the parent compound. ${ }^{27}$

\section{Drug interactions}

Hepatic glucuronidation is the major clearance mechanism for raltegravir, where it is metabolised by UGT1A1. It is not an inhibitor of the UDP-glucuronosyltransferases (UGTs) $1 \mathrm{~A} 1$ and 2B7, and raltegravir does not inhibit P-glycoprotein-mediated transport. Also it does not induce CYP3A4 or inhibit cytochrome P450 CYP isozymes. These data, based on in vitro and in vivo studies, suggest that raltegravir has a low potential to interact with and produce clinically significant changes in the levels of other antiretroviral drugs. This is particularly relevant for those metabolised by the CYP system, including protease inhibitors and non-nucleoside reverse transcriptase inhibitors, or those that are substrates for P-glycoprotein. Overall, raltegravir exhibited a favourable drug-drug interaction profile with other antiretrovirals used in HAART and therefore no dose adjustment is recommended. ${ }^{24}$ However, considerable interand intra-patient variation was seen in the pharmacokinetics of raltegravir. Interaction of raltegravir with some antiretroviral drugs used in combination therapy, based on the geometric mean of pharmacokinetic parameters, may contribute to this variation. ${ }^{24} \mathrm{~A}$ summary of drug interactions with raltegravir is shown in Table 3.

\section{Protease inhibitors}

Atazanavir is an inhibitor of UGT1A1 and therefore has the potential to increase systemic exposure to raltegravir. Ritonavir induces glucuronosyltransferases, inhibiting the metabolism of atazanavir. In two pharmacokinetic studies of healthy subjects the effect of multiple-dose atazanavir or ritonavir-boosted atazanavir on plasma levels of administration of $400 \mathrm{mg}$ raltegravir was assessed and found to increase plasma levels of raltegravir modestly in both scenarios. ${ }^{28}$ Ritonavir alone had minimal effect on plasma levels of raltegravir, suggesting lack of meaningful clinical effect. ${ }^{29,30}$ When administered as combination therapy with raltegravir in treatment-experienced patients a moderate increase in plasma levels was seen but not thought to contribute to the greater antiviral effects of raltegravir. ${ }^{32}$

Tipranavir/ritonavir is a protease inhibitor combination with both inhibitory and inductive potential, including induction of glucuronosyltransferases. A tipranavir/ritonavir combination administered with $400 \mathrm{mg}$ raltgravir to 12 healthy volunteers modestly reduced raltegravir levels. ${ }^{31}$

\section{NNRTIS}

Drug interaction with efavirenz, which has both inhibitory and inductive effects on the CYP enzymes, was evaluated in a placebo-controlled two-period study in healthy volunteers and found to reduce plasma levels of raltegravir, although the clinical significance is not yet known. ${ }^{29}$ The pharmacokinetic interactions of raltegravir and TMC125 a new generation NNRTI, were compared in healthy subjects. TMC125 modestly decreased raltegravir pharmacokinetics, possibly via induction of glucuronidation, whereas raltegravir had no effect on TMC125. Coadministration of TMC125 and raltegravir generally showed a good safety profile and was well tolerated. ${ }^{30}$

\section{NRTI}

The pharmacokinetic profile of raltegravir was studied in an open-label, sequential, three-period study in healthy subjects: raltegravir alone, tenofovir disoproxil fumarate (TDF) alone, and raltegravir in combination with $\mathrm{TDF}$, also in 
Table 3. Pharmacokinetic interaction data with raltegravir (400 mg bid). ${ }^{24}$

\begin{tabular}{|c|c|c|}
\hline Drug & $\begin{array}{l}\text { Interaction } \\
\text { (mechanism, if known) }\end{array}$ & $\begin{array}{l}\text { Recommendations } \\
\text { for co-administration }\end{array}$ \\
\hline \multicolumn{3}{|l|}{ ANTIRETROVIRAL } \\
\hline \multicolumn{3}{|l|}{ Protease inhibitors (PI) } \\
\hline atazanavir/ritonavir & $\begin{array}{l}\text { raltegravir AUC } m 41 \% \\
\text { raltegravir } \mathrm{C}_{12 \mathrm{hr}} m \neq m 7 \% \\
\text { raltegravir } \mathrm{C}_{\max } m 24 \% \\
\text { (UGT1A1 inhibition) }\end{array}$ & No dose adjustment required \\
\hline ritonavir & $\begin{array}{l}\text { raltegravir } \mathrm{AUC})+16 \% \\
\left.\text { raltegravir } \mathrm{C}_{12 \mathrm{hr}}\right)(1 \% \\
\left.\text { raltegravir } \mathrm{C}_{\max }\right)(24 \%\end{array}$ & No dose adjustment required \\
\hline tipranavir/ritonavir & $\begin{array}{l}\text { raltegravir } \mathrm{AUC})(24 \% \\
\left.\text { raltegravir } \mathrm{C}_{12 \mathrm{hr}}\right)(55 \% \\
\left.\text { raltegravir } \mathrm{C}_{\max }\right)(18 \% \\
(\mathrm{UGT} 1 \mathrm{~A} 1 \text { induction) }\end{array}$ & No dose adjustment required \\
\hline $\begin{array}{l}\text { Non-nucleoside reve } \\
\text { efavirenz }\end{array}$ & $\begin{array}{l}\text { itors }(\mathrm{NNRTI}) \\
\text { raltegravir } \mathrm{AUC})(36 \% \\
\left.\text { raltegravir } \mathrm{C}_{12 \mathrm{hr}}\right)(21 \% \\
\left.\text { raltegravir } \mathrm{C}_{\max }\right)(36 \% \\
\text { (UGT1A1 induction) }\end{array}$ & No dose adjustment required \\
\hline \multicolumn{3}{|c|}{ Nucleoside/tide reverse transcriptase inhibitors (NRTI) } \\
\hline tenofovir & 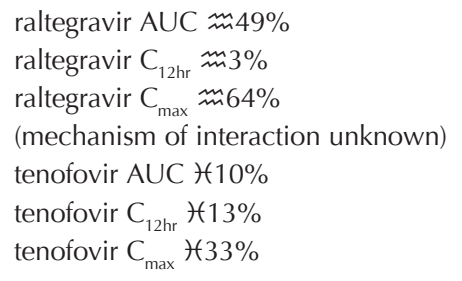 & No dose adjustment required \\
\hline \multicolumn{3}{|l|}{ ANTIMICROBIALS } \\
\hline rifampicin & $\begin{array}{l}\text { raltegravir } \mathrm{AUC})(40 \% \\
\left.\text { raltegravir } \mathrm{C}_{12 \mathrm{hr}}\right)(61 \% \\
\left.\text { raltegravir } \mathrm{C}_{\max }\right)(38 \% \\
\text { (UGT1A1 induction) }\end{array}$ & $\begin{array}{l}\text { Rifampicin reduces plasma levels of raltegravir. If } \\
\text { coadministration with rifampicin is unavoidable, a } \\
\text { doubling of the dose of raltegravir can be considered }\end{array}$ \\
\hline \multicolumn{3}{|l|}{ SEDATIVE } \\
\hline midazolam & $\begin{array}{l}\text { midazolam AUC })(8 \% \\
\text { midazolam } C_{\max } \approx 3 \%\end{array}$ & No dosage adjustment required \\
\hline \multicolumn{3}{|l|}{ ANTI-ULCER } \\
\hline omeprazole & $\begin{array}{l}\text { raltegravir AUC } m 321 \% \\
\text { raltegravir } \mathrm{C}_{12 \mathrm{hr}} m 146 \% \\
\text { raltegravir } \mathrm{C}_{\max } m 415 \%\end{array}$ & $\begin{array}{l}\text { Coadministration of proton pump inhibitors or other } \\
\text { antiulcer medicinal products may increase plasma } \\
\text { levels of raltegravir. } \\
\text { Do not use raltegravir with medicinal products that } \\
\text { increase gastric } \mathrm{pH} \text { unless this is unavoidable. }\end{array}$ \\
\hline
\end{tabular}

HIV-1-infected patients dosed with raltegravir monotherapy versus in combination with lamivudine. There was no clinically significant effect of TDF on raltegravir. Coadministration of raltegravir and TDF does not change the pharmacokinetics of either drug to a clinically meaningful degree. ${ }^{33}$

\section{Antimicrobial}

Rifampicin is a strong inhibitor of glucuronidation and reduces plasma levels of raltegravir by modestly decreasing its pharmacokinetic profile, $\left(\mathrm{C}_{12 \mathrm{hr}}\right.$ by $61 \%, \mathrm{AUC}_{0 \text {-last }}$ by $40 \%$ and $\mathrm{C}_{\max }$ by $38 \%$ ). ${ }^{34}$ If coadministration of raltegravir with rifampicin is necessary, caution is advisable. ${ }^{24}$ 


\section{Special populations}

Hepatic glucuronidation is the major means of drug clearance and since no significant pharmacokinetic differences between healthy subjects and subjects with moderate hepatic impairment have been demonstrated, no dosage adjustments are recommended. However, little is known regarding subjects with severe hepatic impairment and therefore raltegravir should be used with caution in such cases. ${ }^{24}$

\section{Dosing}

The pharmacokinetic profile of raltegravir supports twice-daily dosing, with multiple doses of $100 \mathrm{mg}$ or greater achieving trough levels of $>33 \mathrm{nM}$ in normal healthy volunteers ${ }^{23}$ and in HIV-1-positive patients when administered as monotherapy ${ }^{25}$ or in combination therapy. ${ }^{26}$

In dose-ranging studies using doses of raltegravir ranging from 100 to $600 \mathrm{mg}$, the clinical efficacy in viral load reduction, restoration of immunocompetence, and safety and tolerability profile was similar across each dose. On this basis a middle dose of $400 \mathrm{mg}$ was chosen for Phase III trials. The recommended dose of raltegravir is $400 \mathrm{mg}$ twice daily with or without food. ${ }^{24}$

\section{CLINICAL EFFICACY}

Several placebo-controlled clinical trials have evaluated the clinical efficacy and tolerability of raltegravir in HIV-1-infected patients. Although raltegravir is indicated only for use at $400 \mathrm{mg}$, studies in which other doses have been used are included in this review as background data to show how the licensed dose was derived. This also applies to studies in treatment-naïve patients as raltegravir is available only for use in treatment experienced patients with multi-drug resistance.

\section{Placebo-controlled trials in antiretroviral naïve patients}

In a two-part multicentre placebo-controlled study the tolerability, pharmacokinetic profile and antiviral activity of raltegravir was studied in HIV-positive patients who had a plasma HIV-1 RNA level of 5000 copies/mL or more, a CD4 T-cell count of at least 100cells $/ \mathrm{mm}^{3}$ and who had not previously received antiretroviral therapy.

The first part of this study constituted a shortterm, monotherapy, proof of concept study in which 35 patients received a dose of 100, 200, 400 or $600 \mathrm{mg}$ raltegravir or placebo twice daily for 10 days. Potent antiviral activity was found in all treatment groups compared to placebo, with mean decreases from baseline at day 10 in $\log _{10}$ HIV RNA levels of 1.93, $1.98,1.66$ and 2.16 at 100, 200, 400 and $600 \mathrm{mg}$ raltegravir, respectively. There was no apparent dose response and no statistical difference between treatment groups. However, all groups showed statistically greater reduction than placebo $(\mathrm{P}<0.001)$ (Figure 4$).{ }^{25}$

The second part of this study enrolled 201 treatment-naïve HIV-1-positive subjects (including 30 patients from part 1) into a 48 week combination-therapy trial looking at the efficacy and safety of raltegravir compared with $600 \mathrm{mg}$ /day efavirenz (an NNRTI). Combination therapy comprised tenofovir and lamivudine each at $300 \mathrm{mg} /$ day (both NRTIs) and patients were randomised to receive raltegravir administered at the same dose range as in the first part of the study (100-600 mg twice daily) or placebo. In all treatment groups raltegravir at all doses resulted in a rapid and sustained reduction in HIV-1 RNA levels, with $90 \%$ of patients reaching $<400$ copies $/ \mathrm{mL}$ by week 4 . This effect plateaued but was sustained up to week 24. In contrast efavirenz resulted in a slower response, 
Figure 4. Dose proportional change from baseline at day 10 in $\log 10$ HIV RNA. (Reproduced with kind permission from Markowitz et $a^{25}$ ).

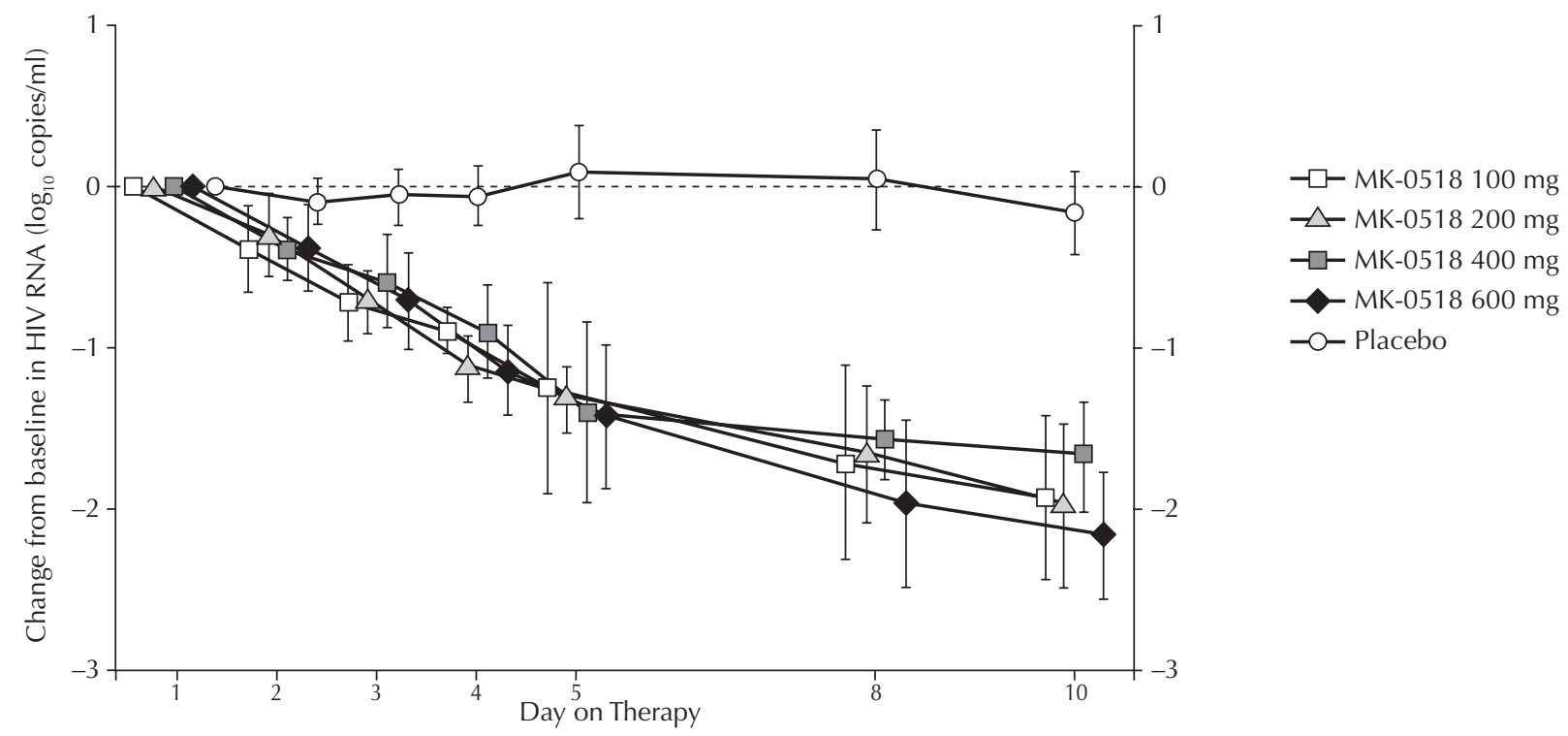

although by week 24 the reduction in viral load to $<50$ copies $/ \mathrm{mL}$ was similar in both treatment groups (up to $95 \%$ of patients). Immunological benefit as indicated by mean increase in CD4 cell count was also greater in the raltegravir group, 139-175 cells $/ \mathrm{mm}^{3}$, compared to 112 cells $/ \mathrm{mm}^{3}$ with efavirenz. Virologic failure was observed in $3 \%$ of patients receiving raltegravir and in these patients virus was identified with mutations in the integrase gene. ${ }^{26}$

In a continuation of this study, doses of raltegravir were standardised to $400 \mathrm{mg}$ twice daily with optimised background therapy (OBT) for all 160 patients and at 96 weeks, the clinical efficacy was sustained with HIV-1 viral load suppression to $<400$ copies $/ \mathrm{mL}$ in $84 \%$ of patients in each group. In an observed-failure analysis of only those patients who completed treatment to 96 weeks, the suppression rates to $<50$ copies $/ \mathrm{mL}$ were $92 \%$ for raltegravir and $91 \%$ for efavirenz. ${ }^{35}$

\section{Combination therapy in antiretroviral experienced patients}

In a multi-centre double-blind placebo-controlled Phase II trial the safety and efficacy of raltegravir was investigated in $179 \mathrm{HIV}$-1- positive patients (plasma HIV-1 RNA >5000 copies/mL) who had experienced antiretroviral therapy for more than three months and demonstrated resistance to at least one NNRTI, NRTI and one protease inhibitor. Patients were randomised to receive raltegravir in the proportions 1:1:1 (200, 400 or $600 \mathrm{mg}$ ) or placebo twice daily in conjunction with OBT. Antiretroviral effects were once again seen as early as week 2 in treatment groups, as viral load was clearly lower, and sustained through 24 weeks. A mean reduction in viral load of $1.80 \log _{10}$ was seen across the raltegravirtreated group compared to placebo $0.35 \log _{10}$ $(\mathrm{p}<0.0001)$. Of the raltegravir-treated group 65.1, 55.6 and 66.7\% with 200, 400 and 600 $\mathrm{mg}$ raltegravir, respectively, demonstrated viral suppression to $<50$ copies/ml, compared to $13.3 \%$ in the placebo group (Figure 5). ${ }^{32}$ 
Figure 5. Virological and immunological responses to raltegravir compared with placebo over 24 weeks in treatmentexperienced patients. Error bars indicate $95 \% \mathrm{Cl}$. (Reproduced with kind permission from Grinsztejn et al. ${ }^{32}$ )

(a) Mean change in viral load from baseline

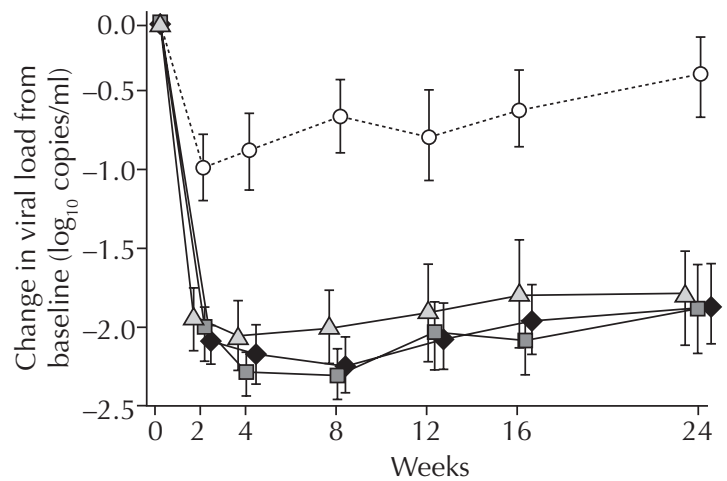

(c) Proportion of patients achieving viral load $<50$ copies $/ \mathrm{mL}$

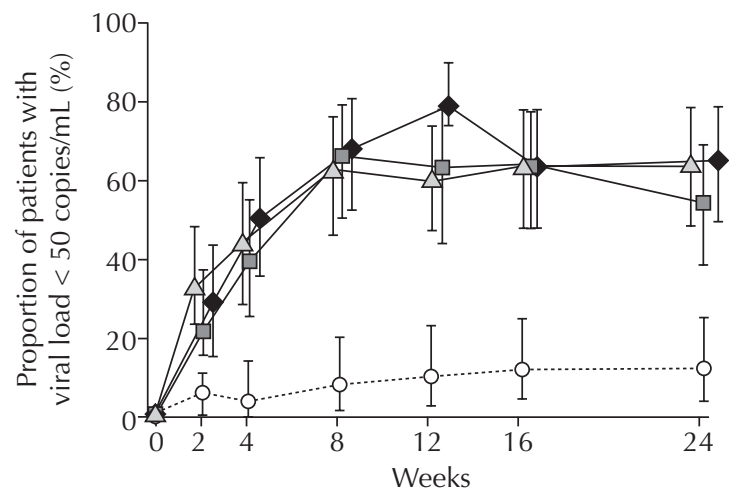

\section{Efficacy in patients with multi-drug resistance}

Enfuvirtide, a fusion inhibitor which acts by blocking viral entry into the host cell, has been successfully used in treatment-experienced patients with multi-drug resistance. However, the need for twice-daily subcutaneous injection has hampered its long-term tolerability with the added problem of injection site reactions. In a small study of 35 patients receiving enfuvirtide an elective switch to orally-administered raltegravir was offered while maintaining their existing virologically suppressive regimen. In all but one case virologic suppression was maintained and the new regimen well tolerated. ${ }^{36}$ (b) Proportion of patients achieving viral load $<400$ copies $/ \mathrm{mL}$

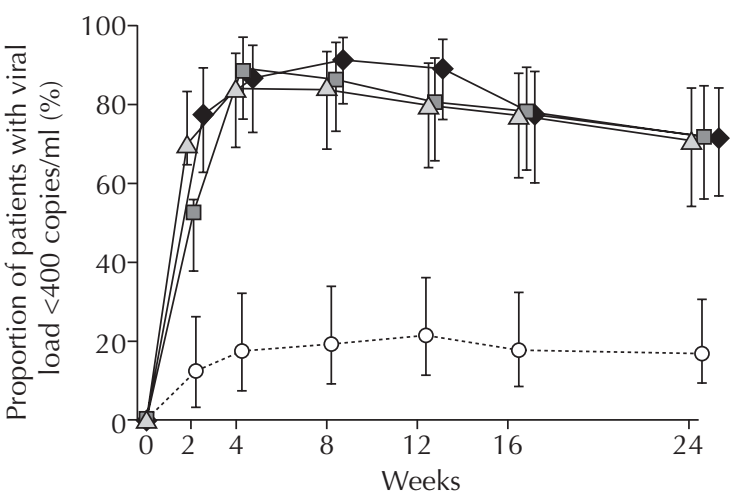

(d) Mean change in CD4 cell count from baseline

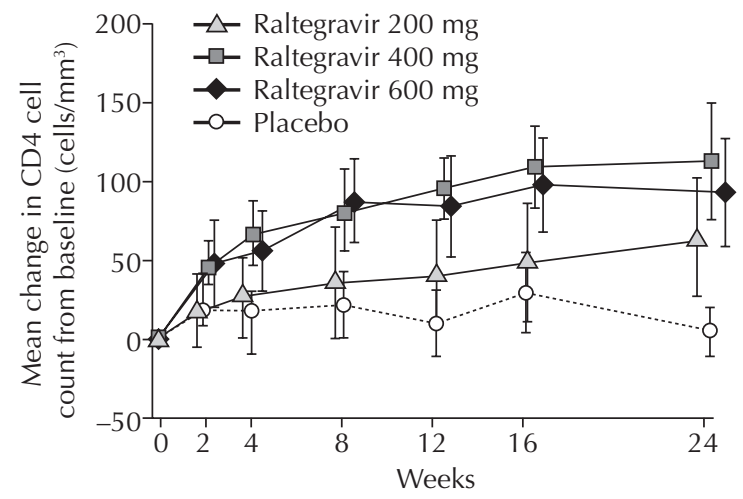

The efficacy of raltegravir in combination with OBT was assessed in 20 patients with triple-class resistant $\mathrm{HIV}-1$ infection. After 10 weeks of raltegravir, $88 \%$ of patients had a viral load reduction to $<400$ copies $/ \mathrm{ml}$, indicating that raltegravir is a potent foundation for therapy in patients with triple-class resistant HIV infection. ${ }^{37}$

\section{Phase III trials: BENCHMRK 1\&2}

Two large identical multicentre placebocontrolled Phase III trials were conducted in different geographic regions to evaluate the safety and efficacy of raltegravir in combination with OBT in HIV-1-positive patients with tripleclass drug resistance and in whom antiretroviral 
therapy had failed. These trials, known as BENCHMRK (Blocking integrase in treatmentExperienced patients with a Novel Compound against HIV, MeRcK), were conducted in Europe, Asia/Pacific and Peru (BENCHMRK-1) ${ }^{38}$ and North and South America (BENCHMRK-2), ${ }^{39}$ respectively. The protocol was identical in both studies and the planned duration of the study was 156 weeks. The results of each individual study at 16 and at 48 weeks have been reported by Cooper et al..$^{38}$ and Steigbigel et al. ${ }^{39}$ as well as the combined results at 48 weeks. $^{40,41}$ The study is ongoing. Baseline characteristics in both studies were similar; mean CD4 count 146-163 cells/ $\mathrm{mm}^{3}$ and HIV-1 RNA levels of 30,000-50,000 copies/mL. Mean duration on antiretroviral therapy was 10 years.

In the combined studies, 699 patients were randomised to receive raltegravir or placebo in a 2:1 ratio. A single dose of $400 \mathrm{mg}$ raltegravir was chosen for the BENCHMRK studies based on previous studies in which no apparent dosedependency in antiviral activity was demonstrated when used at 200, 400 and $600 \mathrm{mg}$ and had acceptable side effects. ${ }^{26,32}$ The OBT was selected for each patient based on history of antiretroviral treatment and baseline genotypic and phenotypic drug-resistance testing. In order to allow for the best possible treatment regimen to be constructed for each patient, darunavir (PI) and enfuvirtide (fusion inhibitor), which were investigational medicines in many countries at the time of this study, were allowed to be included in OBT.

Efficacy endpoints included percentage of patients achieving HIV RNA levels <400 and $<50$ copies $/ \mathrm{mL}$, and the mean change in CD4 cell counts from baseline. At the primary time point of 16 weeks, HIV RNA levels were reduced to $<400$ copies $/ \mathrm{ml}$ in $77.5 \%$ of patients receiving raltegravir, compared to $41.9 \%$ in the placebo group $(\mathrm{p}<0.001)$ and to $<50$ copies/ $\mathrm{mL}$ in $61.8 \%$ and $34.7 \%$ in the raltegravir and placebo groups, respectively $(\mathrm{p}<0.001)$. After 16 weeks, patients who did not show a reduction of viral load of more than $1.0 \log _{10}$ copies/ $\mathrm{mL}$ or to $<400$ copies/mL were considered to be in virologic failure and offered the option to continue, to enter an open label phase and receive raltegravir or opt out altogether. ${ }^{40}$

In the combined analysis at 48 weeks, HIV RNA levels were reduced to $<400$ copies $/ \mathrm{ml}$ in $72.3 \%$ of patients receiving raltegravir, compared to $37.1 \%$ in the placebo group $(\mathrm{p}<0.001)$ and to $<50$ copies $/ \mathrm{mL}$ in $62.1 \%$ and $32.9 \%$ in the raltegravir and placebo groups, respectively $(\mathrm{p}<0.001)$ (Figure 6). ${ }^{40}$

Considering the observed failure approach, the overall mean change in $\log _{10}$ HIV-1 RNA was $-1.7(95 \%$ confidence interval -1.8 to -1.6$)$ and $-0.8(95 \%$ confidence interval -0.9 to -0.6$)$ in the raltegravir and placebo groups, respectively, and mean change in $\mathrm{CD} 4$ cell count from baseline was $109 / \mathrm{mm}^{3}$ and $45 / \mathrm{mm}^{3}$ in the raltegravir and placebo groups, respectively. Investigators concluded that raltegravir combined with OBT provided superior HIV-1 suppression compared with OBT alone. Overall, patients with lower HIV-1 RNA levels and higher CD4 cell counts at baseline had greater response rates. ${ }^{40}$

Although raltegravir had superior efficacy over placebo in patients with a genotypic or phenotypic sensitivity score of 0 , which was in effect monotherapy as there were no fully active drugs in the OBT for those patients, functional monotherapy was not recommended since a greater response was found in patients using active OBT (genotypic or phenotypic sensitivity $>0$ ). The importance of fully active multi-drug therapy was demonstrated by the virologic response rates in patients infected with multi-drug resistant $\mathrm{HIV}-1$. With $\mathrm{PSS}=0,1$ and $>2$ (none, one or two other active drugs in combination with raltegravir) the virologic response rates were $51 \%, 61 \%$ and $71 \%$, respectively (Figure $7 \mathrm{a}$ ). The virologic response rates achieved with raltegravir alone and in 
Figure 6. Clinical efficacy results from the Phase III BENCHMRK trials. Percentage of patients achieving plasma HIV-1 RNA $<400$ copies/mL and $<50$ copies/mL. Results are shown for BENCHMRK-1 (a), BENCHMRK-2 (b), and combined results of both studies (c). (Reproduced with kind permission from Steigbigel et al. ${ }^{40}$ )

(a) BENCHMRK-1

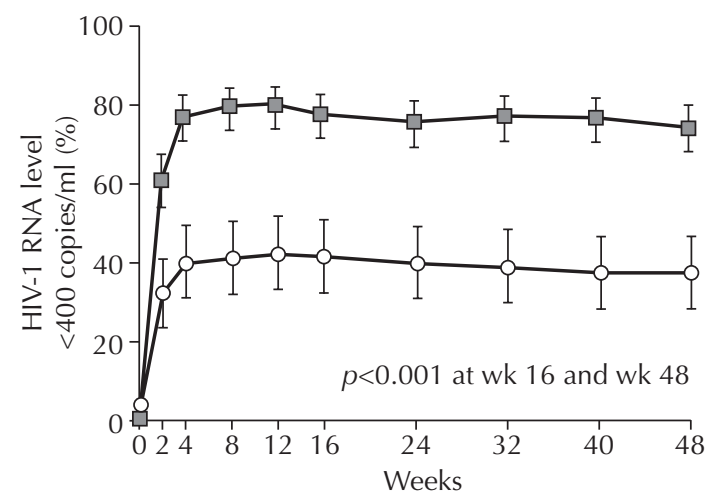

(b) BENCHMRK-2

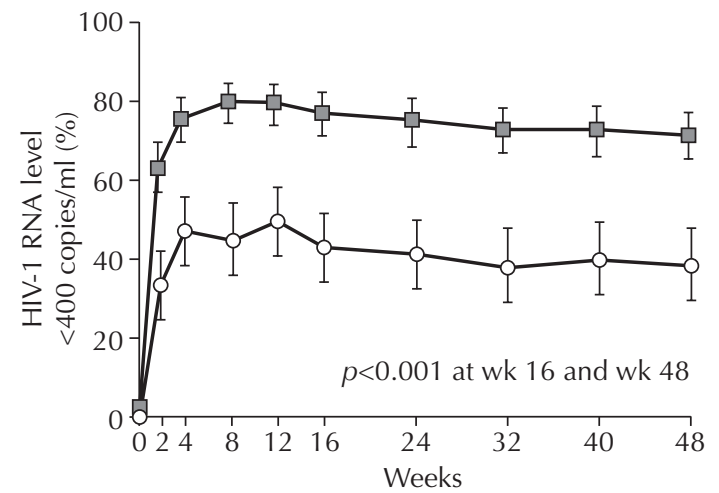

(c) Combined BENCHMRK studies

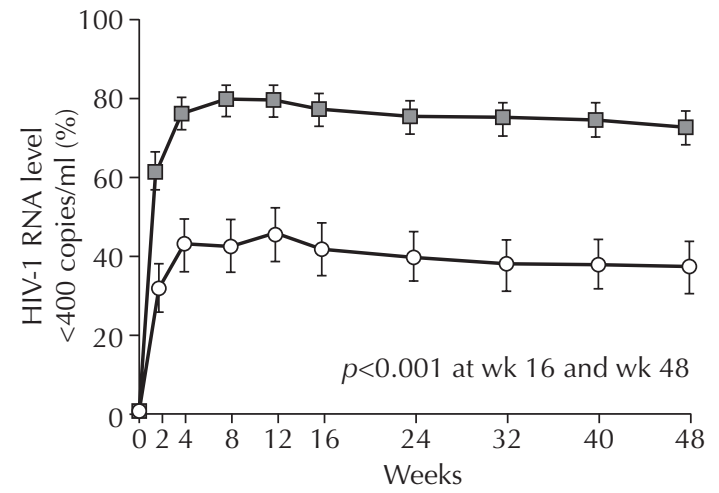

combination with enfuvirtide, darunavir or both enfuvirtide and darunavir were $60 \%, 69 \%, 80 \%$ and $89 \%$, respectively (Figure $7 \mathrm{~b}$ ). ${ }^{38,39}$ These results suggest that even in patients with triple-
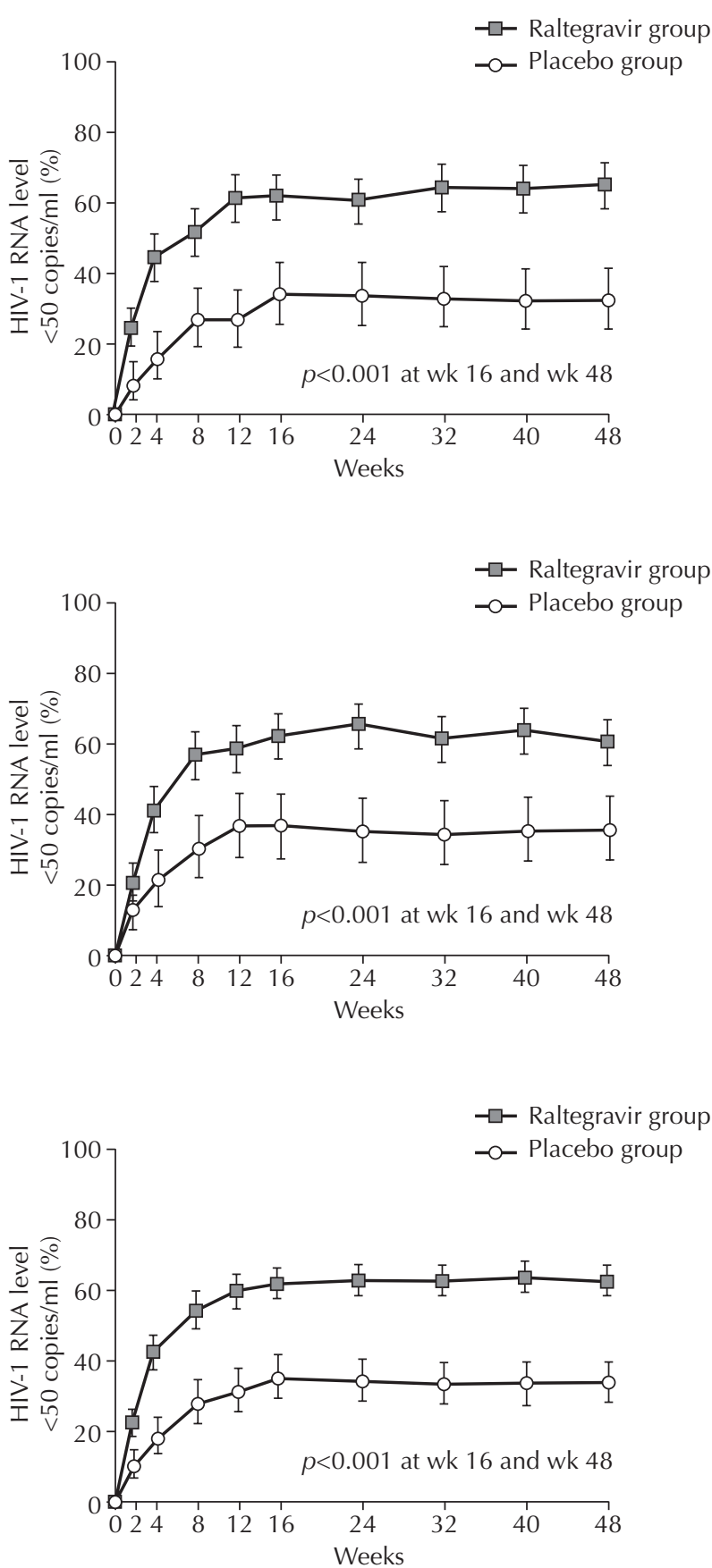

class drug resistance and in whom therapy has failed previously, suppressing viral load to $<50$ copies $/ \mathrm{mL}$ is achievable. 
Figure 7. (a) Percentage of patients with HIV RNA $<50$ copies/mL at week 48 by PSS based on upper and lower cutoffs. Combined results from BENCHMRK-1 and BENCHMRK-2 combined efficancy ${ }^{\dagger}$ (Reproduced with kind permission from Cooper et al. ${ }^{38}$ and Steigbigel et al..$^{39}$ ) (b) Percentage of patients With HIV RNA $<50$ copies $/ \mathrm{mL}$ at week 48 by selected antiretroviral therapy in OBT. Combined results from BENCHMRK-1 and BENCHMRK-2 combined efficancy ${ }^{\dagger}$ (Reproduced with kind permission from Cooper et al..$^{38}$ and Steigbigel et al..$^{39}$ )

(a)

PSS
PSS $=0$ (based on lower cutoff)
PSS $=1$ (based on upper cutoff)
PSS $=1$ (based on upper cutoff)
PSS $\geq 2$ (based on lower cutoff)
PSS $\geq 2$ (based on upper cutoff)
failures carried forward.

(b)

Subgroup
Total Enfuvirtide Darunavir

+ , first use in OBT; - , not used in OBT. ${ }^{+}$Virologic failures carried forward.
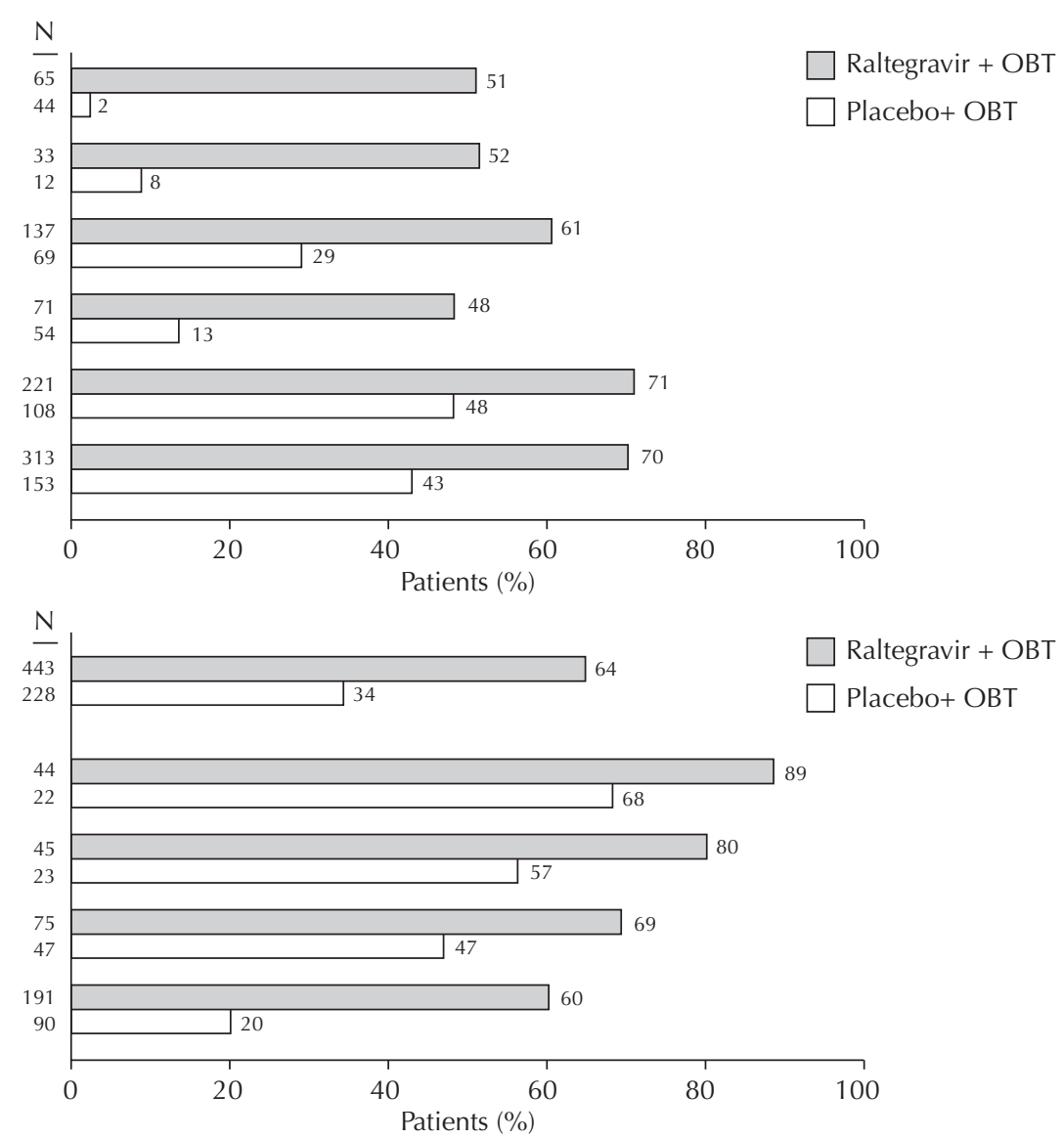

\section{VIROLOGIC FAILURE AND VIRAL RESISTANCE}

The genetic barrier to drug resistance is low. HIV-1 integrase comprises 288 amino acids encoded by the $3^{\prime}$ end of the pol gene, which has three functional domains; the N-terminal zinc-binding domain, the catalytic core and the C-terminal domain involved in DNA binding. Several studies have been undertaken to investigate the genetic mutations in the integrase gene responsible for phenotypic virologic failure following antiretroviral therapy with raltegravir. Although highly drug-resistant strains replicate less efficiently they are still associated with a decline in immune function of the patient, which increases risk of opportunistic infection. ${ }^{7}$

Virologic failure is defined as achieving less than $1.0 \log _{10}$ decrease copies per $\mathrm{mL}$ of viral RNA and not achieving a reduction of viral load to 400 copies $/ \mathrm{ml}$ in response to retroviral therapy on two consecutive measurements at least one week apart. ${ }^{41}$ Virologic failure to raltegravir was found in 3\% of treatment naïve patients ${ }^{26}$ but in treatment-experienced patients with multi-drug resistance, $23 \%$ of patients studied had virologic failure at 48 weeks. ${ }^{41}$

Numerous amino acid substitutions in the HIV integrase have been identified that confer 
resistance to raltegravir. Virologic failure with raltegravir therapy is generally associated with mutations at one of two primary residues, Q148H/K/R or $\mathrm{N} 155 \mathrm{H}$, in combination with at least one other mutation. Substitutions at Y143C and S230R have also been identified and are thought to be involved in later-stage resistance. ${ }^{40,41}$

In a Phase II dose-ranging study, viral resistance to raltegravir was investigated in clinical isolates from 38 patients with virologic failure after 24 weeks' treatment with raltegravir in combination with OBT. In 35 of these patients mutations were identified at one of two locations in integrase gene, N155 or Q148 $\mathrm{H} / \mathrm{R} / \mathrm{K}$, which reduced susceptibility by 10 and 25 fold, respectively. Evolution of secondary mutations (including N155 plus L74M, E92Q G163R or Q148H/R/K plus E138K, $\mathrm{G} 140 \mathrm{~S} / \mathrm{A}$ ) resulted in increased resistance, suggesting that a single point mutation may not be sufficient to confer complete resistance. There was evidence that the virus with Q148 or N155 mutations exhibited cross resistance to other integrase inhibitors that act by binding to the integrase active site. ${ }^{42}$

In a study comparing baseline and on-treatment genotypes of HIV-1 isolates from treatment-failure patients given elvitegravir salvage monotherapy, several mutations associated with resistance to raltegravir were identified, including N155H and Q148. These studies suggest clinically significant crossresistance between these two integrase inhibitors is likely. ${ }^{43}$

Additional mutations associated with raltegravir treatment failure were identified in viral RNA extracts from nine heavily pretreated patients who received salvage therapy including raltegravir and who subsequently suffered virological failure. At least four genetic pathways (E92Q, G140S + Q148H, N155H, and E157Q) may be associated with genotypic and phenotypic resistance to raltegravir. ${ }^{44}$
A subgroup of patients from the combined BENCHMRK studies was evaluated for development of viral resistance. Virologic failure was assessed at 16 weeks and of those patients that continued in the trial, a total of $23 \%$ receiving raltegravir had virologic failure by week 48, including non-completion which constituted failure. Genotypic and phenotypic sensitivity scores for OBT were determined from baseline resistance tests, which indicated the number of antiretroviral drugs to which the patient's HIV-1 was fully susceptible. ${ }^{40}$ Genetic analysis of the integrase gene was performed at baseline and after virologic failure in $90 \%$ of these patients. Of this group 68\% showed genotypic evidence of phenotypic resistance to raltegravir with mutations at Q148, N155 or Y143 and $75 \%$ of those had two or more mutations (Table 4). ${ }^{41}$

The risk of mutations arising during treatment was increased in patients with a higher baseline viral load or receiving OBT with a low genotypic or phenotypic sensitivity score indicating reduced sensitivity to other retroviral drugs. Consequently a lower baseline viral load and use of other antiretrovirals reduce potential for development of viral resistance to raltegravir. Since combination therapy, supported by addressing adherence issues, reduces the risk of virologic failure and development of resistance, these studies support the use of raltegravir in combination with other antiretrovirals rather than as monotherapy. ${ }^{40,41}$

\section{SAFETY AND TOLERABILITY}

Raltegravir was generally well tolerated in all studies with a tolerability and safety profile similar to placebo at all doses tested. The most common drug-related adverse events reported were headache, fatigue, diarrhoea and nausea. ${ }^{23,25,26,32,40,41}$

In a short-term study with normal healthy volunteers receiving single- or multiple-dose oral 
Table 4. HIV-1 integrase resistance mutations arising during the raltegravir treatment period in 94 patients with virologic failure by week 48. (Taken from Cooper et al. ${ }^{41}$ )

\begin{tabular}{|c|c|c|c|c|c|c|}
\hline \multirow[t]{2}{*}{ Resistance mutation in HIV Integrase gene } & \multirow{2}{*}{$\begin{array}{l}\text { Integrase genotyping } \\
\text { performed } \\
(\mathrm{N}=94)\end{array}$} & \multicolumn{3}{|c|}{$\begin{array}{l}\text { Genotypic sensitivity } \\
\text { score at baseline }\end{array}$} & \multirow{2}{*}{$\begin{array}{c}\text { Non } \\
\text { response } \\
(\mathrm{N}=13)^{+}\end{array}$} & \multirow{2}{*}{$\begin{array}{c}\text { Viral } \\
\text { rebound } \\
(\mathrm{N}=81)\end{array}$} \\
\hline & & $0(\mathrm{~N}=49)$ & $1(\mathrm{~N}=27)$ & $\geq 2(\mathrm{~N}=18)$ & & \\
\hline \multicolumn{7}{|c|}{ Number of patients (per cent) } \\
\hline Mutation known to confer raltegravir resistance ${ }^{\S}$ & $64(68)$ & $38(78)$ & $20(74)$ & $6(33)$ & & \\
\hline No amino acid changes from baseline sequence & $25(27)$ & $9(18)$ & $6(22)$ & $10(56)$ & & \\
\hline Amino acid changes of unknown phenotypic effect & $5(5)$ & $2(4)$ & $1(4)$ & $2(11)$ & & \\
\hline \multicolumn{7}{|l|}{ Specific mutation } \\
\hline At amino acid 148, 155, or 143 & & & & & $8(62)$ & $54(67)$ \\
\hline Amino acid 148 & & & & & $3(23)$ & $24(30)$ \\
\hline Q148H & & & & & $1(8)$ & $12(15)$ \\
\hline Q148K & & & & & $1(8)$ & $4(5)$ \\
\hline Q148R & & & & & $1(8)$ & $14(17)$ \\
\hline Amino acid 155 & & & & & $3(23)$ & $35(43)$ \\
\hline Amino acid 143 & & & & & $2(15)$ & $8(10)$ \\
\hline No mutation at amino acid 148,155 , or 143 & & & & & $5(38)$ & $27(33)$ \\
\hline Other raltegravir-resistance mutation* & & & & & 0 & $2(2)$ \\
\hline Amino acid changes of unknown phenotypic effect ${ }^{\uparrow}$ & & & & & $1(8)$ & $4(5)$ \\
\hline No amino acid changes from baseline sequence & & & & & $4(31)$ & $21(36)$ \\
\hline \multicolumn{7}{|c|}{ 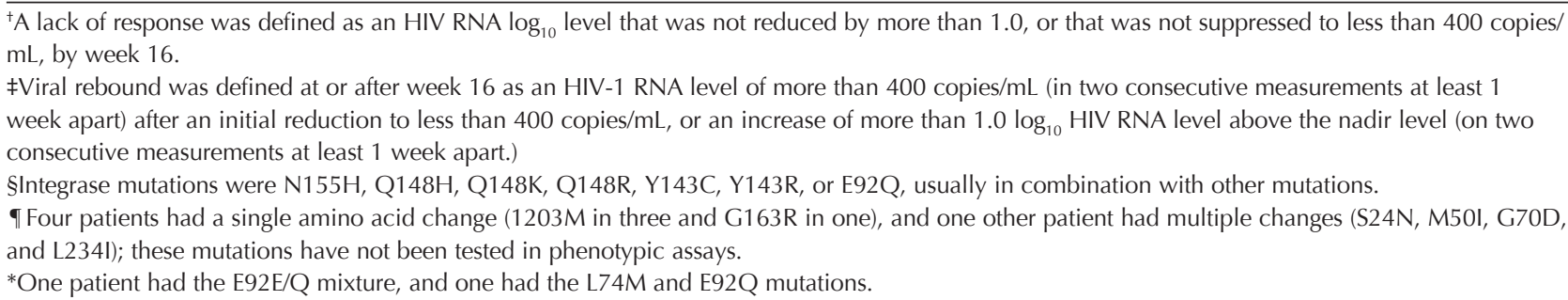 } \\
\hline
\end{tabular}

administration of raltegravir up to $1600 \mathrm{mg}$ for up to 10 days, no serious clinical or laboratory adverse events were reported and there were no discontinuations due to adverse event. ${ }^{23}$

The tolerability and safety profile was evaluated in treatment-naïve patients after 10 days' short-term monotherapy ${ }^{25}$ and after 24 and 48 weeks' combination therapy with tenofovir and lamivudine ${ }^{26}$ when administered twice daily over a concentration range of 100-600 mg. After 10, 24 and 48 weeks most adverse events reported were mild to moderate and there was no association between frequency of adverse events and dose of raltegravir and no dose- related toxicities were seen. In patients receiving raltegravir in combination therapy, the incidence of serious adverse events was $6 \%$, but these were not drug-related and none led to discontinuation. The most common drug-related adverse event (reported with a greater than 10\% incidence) in the raltegravir group was nausea. After 24 and 48 weeks of combination therapy there was no increase in serum levels of total cholesterol, LDL or triglycerides. ${ }^{26}$

In a Phase II trial with treatment-experienced HIV-1 patients receiving combination therapy, raltegravir was well tolerated at all doses (200, 400 and 600mg) after 24 weeks. Drug-related adverse events resulted in discontinuation in four out of 178 patients across all treatment groups. ${ }^{32}$

The combined data from both BENCHMRK trials at an analysis cutoff time of 16 weeks indicated a safety and tolerability profile for the raltegravir regimen similar to the placebocontaining regimen. Clinical adverse events were reported in $90.3 \%$ of patients in the raltegravir treatment group and in $88.2 \%$ in the placebo group, and of these $54.8 \%$ and $55.3 \%$ were 
considered drug-related in the raltegravir and placebo groups, respectively, with headache, diarrhoea and nausea being the most common. Injection site reaction due to enfuvirtide was also reported. In both groups, $2 \%$ of patients died from AIDS-related adverse events. ${ }^{40}$

A similar incidence in laboratory adverse events occurred in raltegravir $(25.5 \%)$ and placebo groups $(23.2 \%)$, and considered to be drug-related in $14.7 \%$ and $13.5 \%$, respectively. Increased serum cholesterol, triglyceride and aminotransferase levels were reported in the raltegravir group and increased cholesterol and creatinine clearance and decreased neutrophil counts were reported in the placebo groups. ${ }^{40}$ The clinical and laboratory adverse events data from the BENCHMRK studies are shown in Table 5.

A disproportionate number of cancers were diagnosed during the double blind phases of the two BENCHMRK studies in the raltegravir groups $(3.5 \%)$ compared with the placebo groups $(1.7 \%)$. Based on these findings a review of the incidence of malignancies in all Phase II and Phase III trials was conducted. The relative risk of cancer associated with raltegravir was $1.2(95 \%$ Cl $0.4-4.1)$ with a composite rate of 2.2 cancers per 100 patient years, compared to

Table 5. Clinical adverse events and laboratory abnormalities during double-blind phases of the BENCHMRK studies. (Taken from Steigbigel et al. ${ }^{40}$ )

\begin{tabular}{|c|c|c|c|c|c|c|}
\hline \multirow[t]{2}{*}{ Event or Abnormality } & \multicolumn{2}{|c|}{ BENCHMRK-1 } & \multicolumn{2}{|c|}{ BENCHMRK-2 } & \multicolumn{2}{|c|}{$\begin{array}{c}\text { Combined BENCHMRK } \\
\text { studies } \\
\end{array}$} \\
\hline & $\begin{array}{c}\text { Raltegravir } \\
\text { Group } \\
(\mathrm{N}=232)\end{array}$ & $\begin{array}{c}\text { Placebo } \\
\text { Group } \\
(N=118)\end{array}$ & $\begin{array}{c}\text { Raltegravir } \\
\text { Group } \\
(\mathrm{N}=230)\end{array}$ & $\begin{array}{c}\text { Placebo } \\
\text { Group } \\
(\mathrm{N}=119)\end{array}$ & $\begin{array}{c}\text { Raltegravir } \\
\text { Groups } \\
(\mathrm{N}=\mathbf{4 6 2})\end{array}$ & $\begin{array}{c}\text { Placebo } \\
\text { Groups } \\
(\mathrm{N}=237)\end{array}$ \\
\hline \multicolumn{7}{|l|}{$\begin{array}{l}\text { Common drug-related clinical adverse event of } \\
\text { moderate-to-severe intensity - no. }(\%)^{+}\end{array}$} \\
\hline Diarrhoea & $6(2.6)$ & $5(4.2)$ & $14(6.1)$ & $5(4.2)$ & $20(4.3)$ & $10(4.2)$ \\
\hline Nausea & $2(0.9)$ & $3(2.5)$ & $9(3.9)$ & $4(3.4)$ & $11(2.4)$ & $7(3.0)$ \\
\hline Headache & $5(2.2)$ & $3(2.5)$ & $7(3.0)$ & 0 & $12(2.6)$ & $3(1.3)$ \\
\hline Fatigue & $1(0.4)$ & 0 & $6(2.6)$ & $2(1.7)$ & $7(1.5)$ & $2(0.8)$ \\
\hline Reaction at injection site & $6(2.6)$ & $4(3.4)$ & $7(3.0)$ & $5(4.2)$ & $13(2.8)$ & $9(3.8)$ \\
\hline Pain at injection site & $5(2.2)$ & $1(0.8)$ & $2(0.9)$ & $1(0.8)$ & $7(1.5)$ & $2(0.8)$ \\
\hline \multicolumn{7}{|l|}{ Laboratory abnormality of grade 3 or $4-\%$} \\
\hline Absolute neutrophil count $<750$ cells $/ \mathrm{mm}^{3}$ & 3.4 & 2.5 & 4.8 & 5.9 & 4.1 & 4.2 \\
\hline Haemoglobin $<7.5 \mathrm{~g} / \mathrm{dl}$ & 1.7 & 0.8 & 0.4 & 0 & 1.1 & 0.4 \\
\hline Platelet count $<50,000 / \mathrm{mm}^{3}$ & 2.6 & 1.7 & 0.4 & 0 & 1.5 & 0.8 \\
\hline Fasting LDL cholesterol $\geq 190 \mathrm{mg} / \mathrm{dl}(4.9 \mathrm{mmol} / \mathrm{l})^{\S}$ & 7.8 & 6.4 & 2.8 & 1.8 & 5.3 & 4.1 \\
\hline Fasting total cholesterol >300 mg/dl $(7.8 \mathrm{mmol} / \mathrm{l})$ & 11.6 & 4.2 & 4.3 & 5.0 & 8.0 & 4.6 \\
\hline Fasting triglycerides >750 mg/dl $(8.5$ mmol/l) & 7.3 & 2.5 & 9.6 & 7.6 & 8.4 & 5.1 \\
\hline Fasting glucose >250 mg/dl (13.9 mmol/l) & 1.7 & 1.7 & 1.7 & 1.7 & 1.7 & 1.7 \\
\hline Creatinine $>1.8 \times$ ULN & 0 & 0 & 2.6 & 2.5 & 1.3 & 1.3 \\
\hline Total bilirubin $>2.5 \times$ ULN & 4.3 & 0.8 & 3.0 & 4.2 & 3.7 & 2.5 \\
\hline Alkaline phosphatase $>5 \times$ ULN & 1.7 & 2.5 & 0.4 & 0.8 & 1.1 & 1.7 \\
\hline Pancreatic amylase $>2 \times$ ULN & 3.9 & 2.5 & 4.8 & 2.5 & 4.3 & 2.5 \\
\hline Lipase $>3 \times$ ULN & 1.7 & 0.8 & 0.4 & 0.8 & 1.1 & 0.8 \\
\hline Aspartate aminotransferase $>5 \times$ ULN & 3.0 & 3.4 & 3.9 & 5.0 & 3.5 & 4.2 \\
\hline Alanine aminotransferase $>5 \times$ ULN & 6.5 & 4.2 & 2.2 & 2.5 & 4.3 & 3.4 \\
\hline Creatine kinase $>10 \times$ ULN & 4.7 & 2.5 & 6.1 & 4.2 & 5.4 & 3.4 \\
\hline
\end{tabular}

${ }^{+}$The clinical adverse events listed are those present in $2 \%$ or more of patients in either treatment group and determined by an investigator to be possibly, probably, or definitely related to the use of a study drug. Reaction at injection site and pain at injection site were considered to be attributable to enfuvirtide injection.

*The laboratory-abnormality grade was assigned on the basis of the DAIDS criteria. Except for creatine kinase, the laboratory test results reported in the table were specified to be graded before the data were unblinded.

${ }^{\S}$ Data on fasting LDL cholesterol were available for 218 patients in each raltegravir group and 109 patients in each placebo group. 
1.8 per 100 patient years in the placebo groups. The types and incidence of cancers reported were similar to those reported in patients with advanced HIV infection. ${ }^{40}$

\section{COST EFFECTIVENESS}

Long-term clinical and economic outcomes of raltegravir use in combination antiretroviral therapy for treatment-experienced patients were evaluated using a cohort state-transition model conducted in Switzerland. The model stratified patients into health states according to their HIV-RNA level, CD4 cell count, and history of opportunistic infections. Data were obtained from clinical trials, published studies, and database analyses. Results were expressed as incremental cost-effectiveness ratios. The study found that addition of raltegravir to OBT would result in substantial survival benefits making it a cost-effective option for treatment experienced HIV patients in Switzerland, concluding that additional cost reductions could be achieved if raltegravir replaces inactive and expensive drugs from the OBT. ${ }^{45}$

\section{KEY POINTS}

- Raltegravir is a specific inhibitor of integrase-catalysed strand transfer, with potent antiretroviral activity in vitro and demonstrated clinical efficacy in patients with HIV-1 infection.

- At all doses of raltegravir administered in Phase II trials (100-600 mg) there was no evidence for a studied dose limiting clinical efficacy or reducing tolerability.

- The pharmacological profile, clinical efficacy and tolerability of raltegravir support twice-daily dosing with $400 \mathrm{mg}$ with or without food as part of combination antiretroviral therapy.

- Twice-daily dosing of $400 \mathrm{mg}$ raltegravir demonstrates superior efficacy when used in combination with OBT over placebo in terms of substantial viral load suppression and increased CD4 cell counts compared to baseline, which is sustained for at least 48 weeks.

- The safety profile of raltegravir is comparable to placebo at all doses studied up to 48 weeks.

- Raltegravir offers an effective treatment option in combination antiretroviral therapy to patients with multi-drug resistant HIV-1 infection and for whom standard therapy is not clinically effective. 


\section{REFERENCES}

1. Palella FJ, Delaney KM, Moorman AC et al. Declining morbidity and mortality among patients with advanced human immunodeficiency virus infection. HIV Outpatient Study Investigators. N Engl f Med 1998; 338: 853-60.

2. Report on the global AIDS epidemic 2008, August 2008. Joint United Nations Programme on HIV/AIDS (UNAIDS) Available at: http://www.unaids.org/en/

3. World Health Organization. Antiretroviral therapy for HIV infection in adults and adolescents: Recommendations for a public health approach. 2006. Available at: http://www. who.int/hiv/pub/guidelines/en/index.html

4. Richman DD. HIV Chemotherapy. Nature 2001; 10: 9951001.

5. Autran B, Carcelain G, Li TS et al. Positive effects of combined antiretroviral therapy on CD4+ T cell homeostasis and function in advanced HIV disease. Science 1997; 277: $112-6$.

6. Evering TH, Markowitz M. Raltegravir: an integrase inhibitor for HIV-1. Expert Opin Investig Drugs 2008;17: 413-22.

7. Shafer RW, Schapiro JM. HIV-1 Drug Resistance Mutations: an Updated Framework for the Second Decade of HAART AIDS Rev. 2008; 10: 67-84.

8. Saksena NK, Potter SJ. Reservoirs of HIV-1 in vivo: implications for antiretroviral therapy. AIDS Rev 2003; 5: 3-18.

9. Chun TW, Nickle DC, Justement JS et al. HIV-infected individuals receiving effective antiviral therapy for extended periods of time continually replenish their viral reservoir. 7 Clin Invest 2005; 115: 3250-5.

10. Potter SJ, Dwyer DE, Saksena NK. Differential cellular distribution of HIV-1 drug resistance in vivo: evidence for infection of CD8+ T cells during HAART. Virology 2003; 305: 339-52.

11. Sabin CA, Hill T, Lampe F et al. Treatment exhaustion of highly active antiretroviral therapy (HAART) among individuals infected with HIV in the United Kingdom: multicentre cohort study. BMF 2005; 330: 695-8.

12. Dayam R, Al-Mawsawi LQ Neamati N. HIV-1 integrase inhibitors: an emerging clinical reality. Drugs RED 2007; 155-68.

13. Al-Mawsawi LQ, Al-Safi RI, Neamati N. Clinical progress of HIV-1 integrase inhibitors. Expert Opin Emerg Drugs 2008; 13: 213-25.

14. Correll T, Klibanov OM. Integrase Inhibitors: A New Treatment Option for Patients with Human Immunodeficiency Virus Infection. Pharmacotherapy 2008; 28: 90-101.

15. Lataillade M, Kozal MJ. The hunt for HIV-1 integrase inhibitors. AIDS Patient Care STDS 2006; 20: 489-501.

16. Hazuda DJ, Felock P, Witmer M et al. Inhibitors of strand transfer that prevent integration and inhibit HIV-1 replication in cells. Science 2000; 287: 646-50.

17. Pommier Y, Johnson AA, Marchand C. Integrase inhibitors to treat HIV/AIDS. Nat Rev Drug Discov 2005; 4: 236-48.

18. Miller M, Witmer M, Stillmock K et al. Biochemical and antiviral activity of MK-0518, a potent HIV integrase inhibitor. Program and abstracts of the XVI International AIDS Conference; August 13-18, 2006; Toronto, Ontario, Canada. Abstract THA0302.
19. Anker M, Corales RB. Raltegravir (MK-0518): a novel integrase inhibitor for the treatment of HIV infection. Expert Opin Investig Drugs 2008; 17: 97-103.

20. Hammer SM, Saag MS, Schechter M et al. Treatment for adult HIV infection: 2006 recommendations of the International AIDS Society-USA panel. FAMA 2006; 296: 827-43.

21. Hammer SM, Eron JJ, Reiss P. Antiretroviral treatment of adult HIV infection: 2008 recommendations of the International AIDS Society-USA panel. FAMA 2008; 300: 555-70.

22. Wenning 1, Anderson M, Petry A et al. Raltegravir (RAL) dose proportionality and effect of food. $46^{\text {th }}$ Interscience Conference on Antimicrobial Agents and Chemotherapy 2006 Sept 17-20. Chicago. Abstract H-256a

23. Iwamoto M, Wenning LA, Petry AS et al Safety, tolerability, and pharmacokinetics of raltegravir after single and multiple doses in healthy subjects. Clin Pharmacol Ther 2008; 83: 293-9.

24. Merck Sharp \& Dohme Limited. Isentress. Summary of Product Characteristics. Sourced from the electronic Medicines Compendium www.emc.medicines.org.uk. Last update January 2008.

25. Markowitz M, Morales-Ramirez JO, Nguyen BY et al. Antiretroviral activity, pharmacokinetics, and tolerability of MK-0518, a novel inhibitor of HIV-1 integrase, dosed as monotherapy for 10 days in treatment-naïe HIV-1-infected individuals. F Acquir Immune Defic Syndr 2006; 43: 509-15.

26. Markowitz M, Nguyen BY, Gotuzzo E et al. Rapid and durable antiretroviral effect of the HIV-1 Integrase inhibitor raltegravir as part of combination therapy in treatment-naive patients with HIV-1 infection: results of a 48-week controlled study. 7 Acquir Immune Defic Syndr 2007; 46: 125-33.

27. Kassahun K, McIntosh I, Gui D et al. Metabolism and disposition in humans of raltegravir (MK-0518), an anti-AIDS drug targeting the human immunodeficiency virus 1 integrase enzyme. Drug Metab Dispos 2007; 35: 1657-63.

28. Iwamoto M, Wenning L, Mistry GC et al. Atazanavir Modestly Increases Plasma Levels of Raltegravir in Healthy Subjects Clinical Infectious Diseases 2008; 47: 137-140.

29. Iwamoto M, Wenning LA, Petry AS et al. Minimal effect of ritonavir (RTV) and efavirenz (EFV) on the pharmacokinetics (PK) of MK-0518. Paper presented at the 46th ICAACAnnual International Conference on Antimicrobial Agents and Chemotherapy, September 27-30, 2006, San Francisco, California, USA, Abstract A-373.

30. Anderson MS, Kakuda TN, Miller JL et al. Pharmacokinetic evaluation of non-nucleoside reverse transcriptase inhibitor (NNRTI) TMC125 and integrase inhibitor (InSTI) raltegravir (RAL) in healthy subjects. Paper presented at the 4th International AIDS Society (IAS) Conference on HIV Pathogenesis, Treatment, and Prevention, July 22-25, 2007, Sydney, Australia, Abstract 2592.

31. Wenning L, Hanley H, Stone J et al. Effect of tipanravir + ritonavir on pharmacokinetics (PK) of MK-0518. Paper presented at the 46th ICAAC-Annual International Conference on Antimicrobial Agents and Chemotherapy, September 27-30, 2006, San Francisco, California, USA, Abstract A-374.

32. Grinsztejn B, Nguyen BY, Katlama C et al. Safety and efficacy of the HIV-1 integrase inhibitor raltegravir (MK-0518) in treatment-experienced patients with multidrug-resistant virus: a phase II randomised controlled trial. Lancet. 2007; 369: 1261-9. 


\section{DRUG PROFILE}

33. Wenning LA, Friedman EJ, Kost JT, et al. Lack of a significant drug interaction between raltegravir and tenofovir. Antimicrob Agents Chemother. 2008 [Epub ahead of print]

34. Iwamoto M, Wenning L A, Liou SY et al. Rifampin (RIF) modestly reduces plasma levels of MK-0518. Presented at the $8^{\text {th }}$ International Congress on drug therapy in HIV infection. Glasgow, UK, November 12-16, 2006. Abstract P299.

35. Markowitz M et al. Sustained antiretroviral efficacy of raltegravir as part of combination ART in treatment-naive HIV-1 infected patients: 96-week data. Seventeenth International AIDS Conference, Mexico City. Abstract TUAB0102.

36. Harris M, Larsen G, Montaner JS. Outcomes of multidrugresistant patients switched from enfuvirtide to raltegravir within a virologically suppressive regimen AIDS 2008; 22: 1224-6.

37. Newmarch LS, Marion CM, Dubin JA, Gottlieb M. Salvage in triple class resistant patients with raltegravir in a community based practice. 7 Investig Med 2008; 56: 189-258.

38. Cooper D, Gatell J, Rockstroh J et al. Results from BENCHMRK-1, a phase III study evaluating the efficacy and safety of MK-0518, a novel HIV-1 integrase inhibitor, in patients with triple-class resistant virus. 14th Conference on Retroviruses and Opportunistic Infections (CROI). Los Angeles, February 25-28, 2007. Abstract 105aLB.

39. Steigbigel R, Kumar P, Eron J et al. Results from BENCHMRK-2, a phase III study evaluating the efficacy and safety of MK-0518, a novel HIV-1 integrase inhibitor, in patients with triple-class resistant virus. 14th Conference on Retroviruses and Opportunistic Infections, Los Angeles, February 25-28, 2007. Abstract 105bLB.

40. Steigbigel R, Cooper D, Kumar $\mathrm{P}$ et al. Raltegravir with optimized background therapy for resistant HIV-1 infection. $\mathcal{N}$ Engl 7 Med 2008; 359: 339-54.

41. Cooper D, Steigbigel R, Gatell J et al. Subgroup and resistance analyses of raltegravir for resistant HIV-1 infection. $\mathcal{N}$ Engl $\mathcal{J}$ Med 2008; 359: 355-65.

42. Hazuda DJ, Miller MD, Nguyen BY. Resistance to the HIVintegrase inhibitor raltegravir: analysis of protocol 005, a phase II study in patients with triple-class resistant HIV-1 infection. Antiviral Ther 2007; 12: S10 Abstract 8.

43. McColl DJ, Fransen S, Gupta S et al. Resistance and cross resistance to first generation integrase inhibitors: insights from a Phase II study of elvitegravir (GS-9137). Antiviral Ther. 2007; 12: S11 Abstract 9.

44. Malet I, Delelis O, Valantin MA et al. Mutations associated with failure of raltegravir treatment affect integrase sensitivity to the inhibitor in vitro. Antimicrob Agents Chemother 2008; 52: 1351-8.

45. Elbasha E, Szucs T, Chaudhary M et al. Cost-effectiveness analysis of Raltegravir in treatment - experienced HIV-1 infected patients in Switzerland. XVII 3-8 August 2008. Abstract TUPDD203.

Correspondence:

Stephen I'Anson, Just Medical Media Ltd, 11 Redgrove Park, Cheltenham, Gloucestershire, GL51 6QY, UK.

Email: publisher@justmedicalmedia.com. 